\title{
Artificial Neural Network Modeling for Biological Removal of Organic Carbon and Nitrogen from Slaughterhouse Wastewater in a Sequencing Batch Reactor
}

\author{
Pradyut Kundu, Anupam Debsarkar, and Somnath Mukherjee \\ Environmental Engineering Division, Civil Engineering Department, Jadavpur University, Kolkata 700032, India \\ Correspondence should be addressed to Somnath Mukherjee; snm_ju@yahoo.co.in
}

Received 30 May 2013; Accepted 4 October 2013

Academic Editor: Manwai Mak

Copyright (C) 2013 Pradyut Kundu et al. This is an open access article distributed under the Creative Commons Attribution License, which permits unrestricted use, distribution, and reproduction in any medium, provided the original work is properly cited.

\begin{abstract}
The present paper deals with treatment of slaughterhouse wastewater by conducting a laboratory scale sequencing batch reactor (SBR) with different input characterized samples, and the experimental results are explored for the formulation of feedforward backpropagation artificial neural network (ANN) to predict combined removal efficiency of chemical oxygen demand (COD) and ammonia nitrogen $\left(\mathrm{NH}_{4}{ }^{+}-\mathrm{N}\right)$. The reactor was operated under three different combinations of aerobic-anoxic sequence, namely, $(4+4),(5+3)$, and $(5+4)$ hour of total react period with influent COD and $\mathrm{NH}_{4}{ }^{+}-\mathrm{N}$ level of $2000 \pm 100 \mathrm{mg} / \mathrm{L}$ and $120 \pm 10 \mathrm{mg} / \mathrm{L}$, respectively. ANN modeling was carried out using neural network tools, with Levenberg-Marquardt training algorithm. Various trials were examined for training of three types of ANN models (Models "A," "B," and "C") using number of neurons in the hidden layer varying from 2 to 30 . All together 29, data sets were used for each three types of model for which 15 data sets were used for training, 7 data sets for validation, and 7 data sets for testing. The experimental results were used for testing and validation of three types of ANN models. Three ANN models (Models "A," "B," and "C") were trained and tested reasonably well to predict COD and $\mathrm{NH}_{4}{ }^{+}$-N removal efficiently with $3.33 \%$ experimental error.
\end{abstract}

\section{Introduction}

The sequencing batch reactor (SBR) is the most promising and viable of the proposed activated sludge modifications for the removal of organic carbon and nutrients [1]. Due to its simplicity and flexibility of operation, it has become increasingly popular for the biological treatment of domestic and industrial wastewater [2]. The most common (aerated) SBR is a fill-and-draw activated sludge system for wastewater treatment. Equalization, aeration, and clarification can all be performed in a single batch reactor. In general, SBR systems have a relatively small footprint; they are useful for areas where the available land is limited. In addition, system cycles can be easily modified, making SBRs extremely flexible to adapt to more restrictive effluent quality standards by public authorities. The determination of the influent characteristics and effluent requirements, site specific parameters such as temperature, and key design parameters such as nutrientto-biomass ratio, treatment cycle duration, suspended solids, and hydraulic retention time is imperative to establish the operation sequence of the SBR. It allows calculating the number of cycles per day, number of basins (batches), decanting volume, reactor size, and detention times. For most industrial wastewater applications, treatability studies have typically been required to determine the optimum operating sequence. Slaughterhouse wastewater is mainly composed of diluted blood, protein, fat, and suspended solids. Organic carbon and nitrogen are major contaminants of concern in the wastewater. The aim of this study consists in the identification of suitable operation conditions for a cycle according to characteristics of influent wastewater, treatment requirements, and effluent quality using a SBR technology for simultaneous removal of organic carbon and nitrogen from slaughterhouse wastewater and discusses some aspects 
on process optimization based on artificial neural network (ANN) model.

Artificial neural networks (ANNs) are now used in many areas of science and engineering and considered as promising tool because of their simplicity towards simulation, prediction, and modeling $[3,4]$. The advantages of ANN are that the mathematical description of the phenomena involved in the process is not required; less time is required for model development than the traditional mathematical models and prediction ability with limited numbers of experiments [57]. Application of ANN to solve environmental engineering problems has been reported in many articles. ANNs were applied in biological wastewater treatment and physicochemical wastewater treatment [8-10].

ANNs are mathematical systems comprised of a number of "processing units" that are linked via weighted interconnections. The tool helps in mapping a set of input data into a corresponding set of output data after learning a series of past process data from a given system. Moreover, the neural network model possesses a distinctive ability of learning nonlinear functional relationship without requiring a structural knowledge of the process to be modeled. Several examples of successful development of software sensor mechanism based on the neural network approach are described in the literature [11-14]. The application of ANN modeling in environmental engineering field is, however, still being undergone. A sizeable number of ANN modeling in wastewater treatment are used to explore its application potential for predicting experimental data aiming for enhancing efficiency and optimizing the WWTP [15-18].

The objective of the present study was application of feedforward backpropagation artificial neural network (ANN) modeling to predict the performance of a laboratory scale sequencing batch reactor operated under three different combinations of aerobic-anoxic sequential hours of cycles, namely, ( 4 hour aerobic +4 hour anoxic), (5 hour aerobic +3 hour anoxic), and (5 hour aerobic +4 hour anoxic) of total react period in terms of COD removal and $\mathrm{NH}_{4}{ }^{+}$$\mathrm{N}$ reduction from real life slaughterhouse wastewater as output parameters in correspondence with various input parameters of influent $\mathrm{COD}$ and $\mathrm{NH}_{4}{ }^{+}-\mathrm{N}$ concentration, microbial concentration, contact time, $\mathrm{pH}$, dissolved oxygen (DO), and so forth. The data used for ANN formulation were obtained from experimental investigation as carried out in the laboratory by the authors.

\section{Material and Methods}

2.1. Seed Acclimatization for Combined Carbon Oxidation and Nitrification. Heterotrophic microbes were actively acclimatized in the laboratory environment by inoculating sludge collected from an aeration pond of a small-scale slaughterhouse located nearby to the institute. The mixture of sludge was continuously aerated with intermittent feeding with dextrose solution having concentrations of $1000 \mathrm{mg} / \mathrm{L}$ and ammonium chloride $\left(\mathrm{NH}_{4} \mathrm{Cl}\right)$ having concentration of $200 \mathrm{mg} / \mathrm{L}$ as a carbon and nitrogen source, respectively. The acclimatization process was continued for an overall period of 90 days. The biomass growth was monitored by

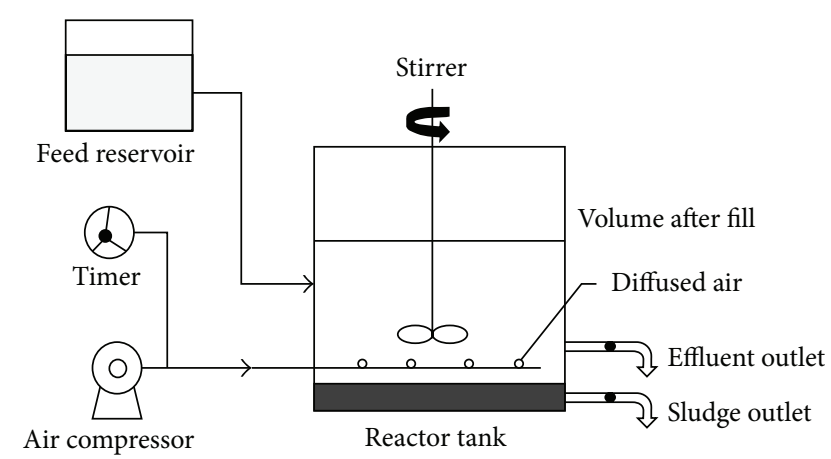

FigURE 1: Experimental setup of SBR.

the magnitude of sludge volume index (SVI) and mixed liquor suspended solid (MLVSS) concentration in the reactor. $\mathrm{pH}$ in the reactor was maintained in the range $6.8-7.5$ by adding required amount of sodium carbonate $\left(\mathrm{Na}_{2} \mathrm{CO}_{3}\right)$ and phosphate buffer. The seed acclimatization phase was considered to be over when a steady state condition was observed in terms of equilibrium $\mathrm{COD}$ and $\mathrm{NH}_{4}{ }^{+}-\mathrm{N}$ reduction with respect to a steady level of MLVSS concentration and SVI in the reactor.

Denitrifying seed was cultured separately in $2.0 \mathrm{~L}$ capacity aspirator bottle under anoxic condition. $500 \mathrm{gm}$ of digested sludge obtained from a local sewage treatment plant (STP) was added to $1.0 \mathrm{~L}$ of distilled water. The solution was filtered and added to $500 \mathrm{~mL}$ of untreated slaughterhouse wastewater. The resulting solution was acclimatized for denitrification purpose using dextrose as carbon source and potassium nitrate $\left(\mathrm{KNO}_{3}\right)$ as the source of nitrate nitrogen $\left(\mathrm{NO}_{3}{ }^{-}\right.$$\mathrm{N})$. Magnetic stirrer was provided for proper mixing of the solution. Denitrifying seed was acclimatized against a nitratenitrogen concentration varying from 10 to $90 \mathrm{mg} / \mathrm{L}$ as $\mathrm{N}$, over a period of three months.

2.2. Experimental Setup. The experiment that was performed in a laboratory scale sequencing batch reactor of $20.0 \mathrm{~L}$ effective volume was fabricated by Plexiglass sheet of $6 \mathrm{~mm}$ thickness which is shown schematically in Figure 1. The feed solution was kept in a $25.0 \mathrm{~L}$ capacity carboy placed up on an elevated wooden platform. A feed tube as inlet was connected from the bottom of carboy to the inlet spout of the reactor. The air is supplied through a belt-driven air compressor. The air from compressor supplied to a diffuser system which is made up of glass tube with $2 \mathrm{~mm}$ opening size in a single assembly and provided $50 \mathrm{~mm}$ above the bottom of the SBR. The compressed air was supplied to the reactor through the above openings. Treated water was withdrawn from an outlet placed at $100 \mathrm{~mm}$ above the bottom of the reactor. A stirrer of $0.3 \mathrm{hp}$ capacity is installed centrally for agitating and mixing the content of the reactor. The air supply was stopped during anoxic mode of the react period. During this phase only, the stirrer was allowed to operate. A timer was connected to compressor for controlling the aeration period. A sludge withdrawal port was also provided near the bottom of the reactor. 


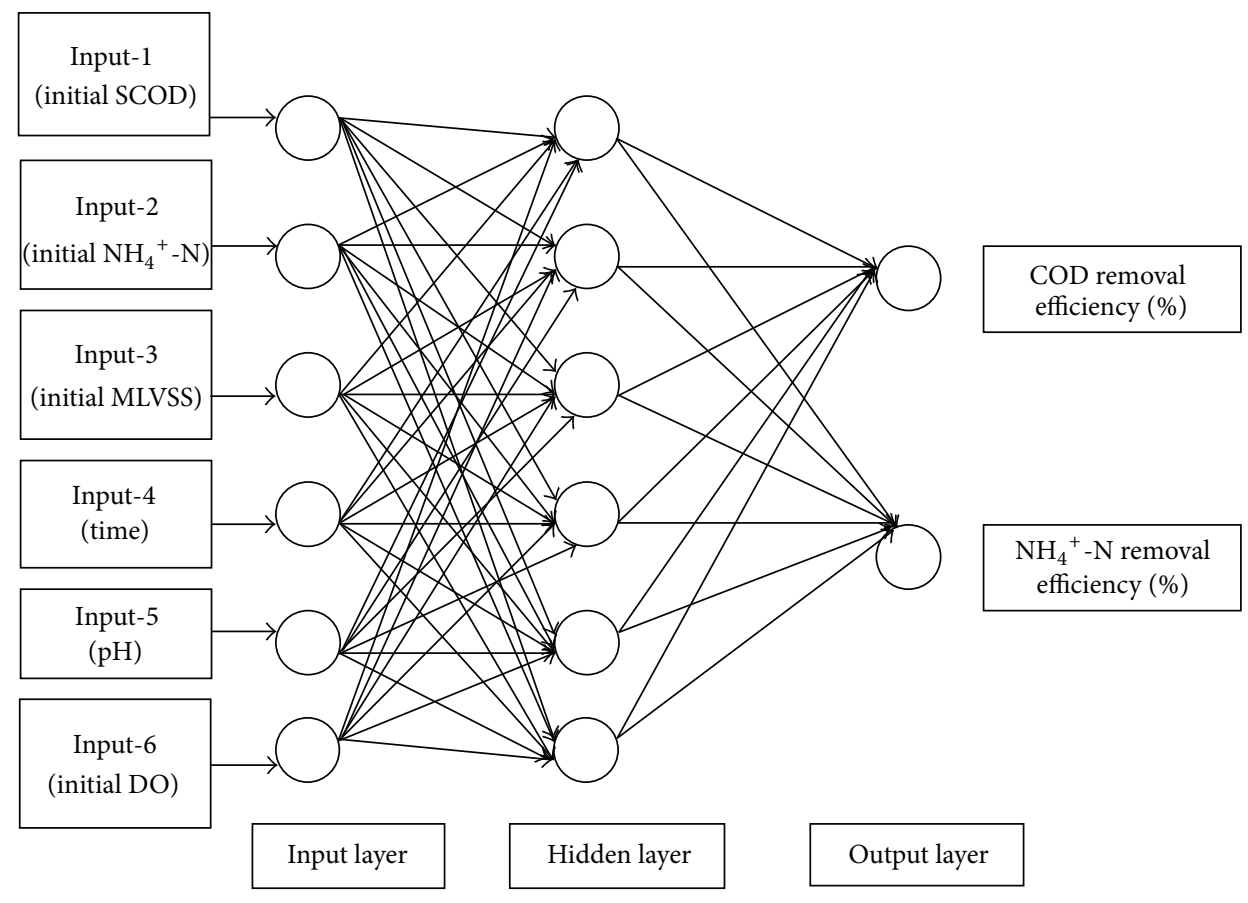

FIGURE 2: Architecture of ANN Model.

2.3. Experimental Procedure. The treatability study of slaughterhouse wastewater in SBR was investigated for the wastewater sample collected from outlet of the slaughterhouse, as mentioned above. The raw and primary-treated wastewater was first characterized and subsequently treatability experiment was carried out in the laboratory scale SBR unit. The following analytical parameters, namely, $\mathrm{pH}$, TSS, VSS, DO, $\mathrm{BOD}_{5}$ at $20^{\circ} \mathrm{C}, \mathrm{COD}, \mathrm{TKN}$, and $\mathrm{NH}_{4}{ }^{+}-\mathrm{N}$ were estimated for the wastewater characterization of the slaughterhouse effluent. The analytical parameters were determined following the protocols as described in "Standard Methods" [19]. For each parameter testing three sets of replicates were considered. A mixed liquor of $2.5 \mathrm{~L}$, containing mixed sludge as acclimatized previously, was taken into SBR containing 20.0 L volume of pretreated slaughterhouse wastewater. The performance study was carried out with pretreated slaughterhouse wastewater having an average initial chemical oxygen demand (COD) of $2000 \pm 100 \mathrm{mg} / \mathrm{L}$ and ammonia nitrogen $\left(\mathrm{NH}_{4}{ }^{+}-\mathrm{N}\right)$ concentration of $120 \pm 10 \mathrm{mg} / \mathrm{L}$. The volatile suspended solid (VSS) to suspended (SS) ratio of the sludge was 0.783 . After seeding, MLVSS concentration in the SBR reactor was found to be $2200 \pm 400 \mathrm{mg} / \mathrm{L}$. The duration of a complete cycle was 10.0 to 11.0 hour, giving two complete cycles per day. The total cycle period consisted of a fill period of 0.5 hour, overall react period of 8.0 to 9.0 hour, settle period of 1.0 hour, and decant period of 0.5 hour with two cycles per day. In the carbon oxidation and nitrogen removal study, the overall react period was divided into aerobic and anoxic react periods with following three combinations:

Combination-1: 4-hour aerobic react period and 4hour anoxic react period;
Combination-2: 5-hour aerobic react period and 3hour anoxic react period;

Combination-3: 5-hour aerobic react period and 4hour anoxic react period.

In the ammoniacal nitrogen removal phase, the reactor was continuously aerated by a compressor of capacity $0.25 \mathrm{hp}$. during the fill period and for the entire aerobic react phase. The mechanical mixer was operated continuously with a speed of $400 \mathrm{rpm}$ from the beginning of the fill phase to the end of the total react phase for proper mixing of liquid in the reactor. During the draw phase, the supernatant wastewater that was decanted until the liquid volume in the reactor decreased to $4.0 \mathrm{~L}$. SRT (solid retention time) was manually controlled by withdrawal of volume of the mixed liquor from the reactor every day at the onset of the commencement of settle phase. The reactor was continuously run for 120 days. The treated volume of slaughterhouse wastewater was taken as $16 \mathrm{~L}$. The initial $\mathrm{pH}$ values in the reactor were kept in between 7.0 and 8.0, whereas the sludge volume index (SVI) has been kept within the range of $75-85 \mathrm{~mL} / \mathrm{gm}$, for obtaining good settling property of the biomass. The SRT of 20-25 days is maintained for carbon oxidation and nitrification in the present SBR system for treatment of wastewater as suggested by Tremblay et al. [20].

During the time course of the study, $100 \mathrm{~mL}$ of sample was collected from the outlet of the reactor at every 1.0 hour interval, after completion of the fill period. The samples were analyzed for the following parameters, namely, $\mathrm{pH}, \mathrm{DO}$, MLSS, MLVSS, COD, $\mathrm{NH}_{4}{ }^{+}-\mathrm{N}, \mathrm{NO}_{2}{ }^{-}-\mathrm{N}$, and $\mathrm{NO}_{3}{ }^{-}-\mathrm{N}$ as per "Standard Methods" [19]. The $\mathrm{pH}$ of the solution was measured by a digital $\mathrm{pH}$ meter. $\mathrm{NH}_{4}{ }^{+}-\mathrm{N}, \mathrm{NO}_{2}{ }^{-}-\mathrm{N}$, and 
$\mathrm{NO}_{3}{ }^{-}-\mathrm{N}$ were estimated by respective ion selective electrodes meter. COD was analyzed by closed reflux method in digester. Dissolved oxygen (DO) was measured electrometrically by digital DO meter. Mixed liquor suspended solids (MLSS) and mixed liquor volatile suspended solids (MLVSS) were measured by gravimetric method at the temperature of 103$105^{\circ} \mathrm{C}$ in oven and $550 \pm 50^{\circ} \mathrm{C}$ in muffle furnace, respectively.

2.4. Artificial Neural Network Modeling. The architecture of ANN consists of input layer, one or more hidden layer, and output layer. Each layer of the network consists of a number of interconnected processing elements called as neurons. These neurons interact with each other with the help of the weight. Each neuron is connected to all the neurons in the next layer. The data is presented to the neural network in the input layer. The output of the neural network is presented by output layer for the given input data. The hidden layers enable these networks to compute complicated relations between input and output. The structure of feedforward neural network is exhibited in Figure 2.

The number of hidden layers is to be selected in respect of the complexity of the problem. Generally one hidden layer is sufficient for investigation of most of the problem. The number of neurons in the hidden layer is selected by trial and error method starting from minimum value and then to be increased depending on the nature of problem. The training of neural network is carried out by presenting a series of input data and target output values. The parameters affecting the output should be selected as input parameters. The backpropagation training algorithm has been widely used to model various problems in environmental engineering. In the backpropagation training algorithm, the neurons in the hidden layer and output layer process its input by multiplying each input by its weight, summing the product, and then processing the sum using a nonlinear transfer function, also called activation function, to produce results. The most common transfer function used is the sigmoid function. The learning in the neural network takes place by modifying weights of the neurons according to the error between the actual output value and the target output values. The changes in weight are proportional to negative of the derivative of the error.

The backpropagation is essentially a gradient descending method to minimize the network error function equation:

$$
E=\sum_{j=1}^{k} \sum_{i=1}^{n}\left(e_{i}(j)-t_{i}(j)\right)
$$

where $e_{i}(j)$ and $t_{i}(j)$ are estimated and targeted values, respectively. " $n$ " is the number of output nodes, and " $k$ " is the number of training samples.

Before starting training of an ANN, weights are initially randomized. Based on the error propagation, weights are adjusted based on

$$
\Delta W_{i j}(n)=\alpha \frac{d E}{d W_{i j}}+\eta \Delta W_{i j}(n-1),
$$

where $W_{i j}(n)$ and $W_{i j}(n-1)$ are the weights increment between nodes $i$ and $j$ during the adjacent iteration and $\alpha$ and $\eta$ are learning rate and momentum factor. Careful selection and appropriate adjustment of the learning rate are very much necessary for successful training of backpropagation neural network. Some earlier contributory works were cited in various literatures in reference to ANN modeling on nutrient removal in biological reactor $[21,22]$.

The training of ANN model was carried out by presenting the complete input data set to the network and continued till the average MSE is minimized. After the training is over, the trained neural network deemed to be reproduced by the target output values for provided training data. Weights of the trained neurons are then stored in the neural network memory. Testing of the trained network is carried out by presenting the set of test data and then comparing the output of the network with the actual values of the output. The performance of formulated ANN model can be measured by several statistical parameters, such as coefficient of determination $(R)$, MSE, and RMSE. A well-trained model should have $R$ value close to 1 and error should be least.

The numbers of input and output neurons are fixed according to the nature of the problem. In the present study, only one hidden layer was selected. The number of neurons in the hidden layer was selected from 2 to 30 . The inputs to the neural network include the amount of MLVSS ( $\mathrm{mg} / \mathrm{L})$, initial concentration of COD $(\mathrm{mg} / \mathrm{L})$, initial concentration of $\mathrm{NH}_{4}{ }^{+}$$\mathrm{N}(\mathrm{mg} / \mathrm{L}), \mathrm{pH}$, and contact time (hour). The percentage removal of $\mathrm{COD}$ and $\mathrm{NH}_{4}{ }^{+}-\mathrm{N}$ was selected as targets.

2.5. Data Preprocessing. The input and output variables in the present study consist of different characteristics and importance level, resulting into varying response to the neural network. The ANN model training would be more efficient if preprocessing steps are to be performed on the input and target data, by making the preprocessing exercise useable in real applications. The input parameters were scaled up in the range 0.2 to 0.8 . The preprocessing of the data could be performed by the algorithm as given in

$$
X_{i}(\text { net })=0.2+0.6 \frac{\left(X_{i m}-\min \left(X_{i}\right)\right)}{\max \left(X_{i}\right)-\min \left(X_{i}\right)},
$$

where $X_{i}$ (net) is normalized value of $i$ th variable; $X_{i m}$ is observed value of $i$ th variable; $\min \left(X_{i}\right)$ is minimum value of $i$ th observed variable in the training data-set; $\max \left(X_{i}\right)$ is maximum value of $i$ th observed variable in the training dataset.

After preprocessing of the training data set, the new input sets are fed into the trained networks with minimum and maximum vectors for the training set. In order to compare the neural network results with the observed results, the rescaled outputs need to be converted back within the same range for the original targets. The algorithm as given in (4) was used for this purpose:

$$
Y_{i(p)}=\min Y_{i}+\frac{\left(\max Y_{i}-\min Y_{i}\right)}{0.6} \times\left(X_{i}(\text { net })-0.2\right),
$$

where $Y_{i(p)}$ is predicted value of $i$ th output variable; $X_{i}$ (net) is normalized value of $i$ th output variable; $\min Y_{i}$ is minimum 
value of $i$ th observed variable in the training data-set; $\max Y_{i}$ is maximum value of $i$ th observed variable in the training data-set.

2.6. ANN Software. A three-layered feedforward neural network with backpropagation training algorithm was used to validate the ANN model. The tangent-sigmoid transfer functions (tansig) in between input and hidden layer and a linear transfer function (purelin) in between hidden layer and output layer were used. The Levenberg-Marquardt algorithm was used for ANN model training. During training process, small weights were assigned to the connection between neurons in a random way. Weights were modified until the error between the predicted and experimental values of adsorption efficiency are minimized. It is desired that the difference between predicted and observed values should be as small as possible. During testing process, the network was tested for its generalization ability with the observed output after the training process was completed. When the neural networks are tested successfully, they can be used for prediction.

The feedforward backpropagation (BP) algorithm with Levenberg-Marquardt training was applied for neural network model development. The BP is an approximate steepest descent algorithm where an MSE is used as performance function. In the neural network development, different number of hidden layers, the number of neurons in each layer, and the type of transfer function for each neuron were analyzed all with a learning rate of 1.0 [23] and training goal of $10^{-5}$. Then, the trained networks were tested using the testing data sets and the MSE method by modifying the network weights.

2.7. Performance of Developed ANN Model. In order to measure the pollutant removal efficiency and the performance of three neural network models developed for biological system, different types of statistical parameters were used to estimate the error. In the present work, ME, MSE, and RMSE were selected to measure the network performance of Models "A," "B," and "C" under three different combinations of aerobic-anoxic sequence, namely, $(4+4),(5+3)$, and $(5+4)$ hour of total react period, respectively, for treatment of slaughterhouse wastewater in SBR. Furthermore, a linear regression analysis between the predicted values and actual experimental values was carried out to investigate the network response for establishing the removal efficiencies of organic matter as $\mathrm{COD}$ and nitrogen matter as $\mathrm{NH}_{4}{ }^{+}-\mathrm{N}$ in SBR system.

2.8. Optimization of ANN Model. The optimal architecture of the ANN model and its parameter variation were determined based on the minimum value of the MSE of the training and prediction set as suggested by Ekici and Aksoy [24]. To start the training, initially 2 neurons were taken in the hidden layer and it was then increased up to 30 neurons:

$$
\operatorname{MSE}=\frac{1}{N} \sum_{i=1}^{N}\left(T_{i}-A_{i}\right),
$$

TABLE 1: Characteristics and composition of slaughterhouse wastewater.

\begin{tabular}{lcc}
\hline $\begin{array}{l}\text { Parameters } \\
\text { (all units are in mg/L except } \mathrm{pH})\end{array}$ & $\begin{array}{c}\text { Raw } \\
\text { wastewater } \\
\text { range }\end{array}$ & $\begin{array}{c}\text { Pre treated } \\
\text { wastewater } \\
\text { range }\end{array}$ \\
\hline $\mathrm{pH}$ & $8.0-8.5$ & $7.5-8.5$ \\
Total suspended solids & $10120-14225$ & $4255-5340$ \\
Total dissolved solids & $6345-7840$ & $2800-3830$ \\
$\mathrm{COD}$ & $4185-5240$ & $1930-2096$ \\
$\mathrm{BOD}_{5}$ at $20^{\circ} \mathrm{C}$ & $3000-3500$ & $1010-1465$ \\
Total Kjeldahl nitrogen $(\mathrm{TKN})$ & $450-560$ & $315-412$ \\
$\mathrm{NH}_{4}{ }^{+}-\mathrm{N}$ (as N) & $215-310$ & $110-130$ \\
\hline
\end{tabular}

where $N$ is number of data points; $T_{i}$ is network predicted value at the $i$ th data; $A_{i}$ is experimental value at the $i$ th data; $i$ is an index of the data.

\section{Results and Discussions}

3.1. Characterization of Slaughterhouse Wastewater. The slaughterhouse wastewater samples were collected from two different locations: (i) the raw (untreated) wastewater from the main collection pit and (ii) the primary treated effluent from the inlet box of aeration basin. The wastewater samples were collected 6 (six) times over the entire course of the study in $25.0 \mathrm{~L}$ plastic containers and stored in a refrigerator at approximately $4.0^{\circ} \mathrm{C}$. The above wastewater samples (raw and primary treated) were characterized in the laboratory with respect to the parameters as exhibited in Table 1 . The performance of the present study was carried out with wastewater having an average initial chemical oxygen demand (COD) of $2000 \pm 100 \mathrm{mg} / \mathrm{L}$ and ammonia nitrogen $\left(\mathrm{NH}_{4}{ }^{+}-\mathrm{N}\right)$ concentration of $120 \pm 10 \mathrm{mg} / \mathrm{L}$ as $\mathrm{N}$.

\subsection{Treatment of Slaughterhouse Wastewater for Carbon} Oxidation and Nitrogen Removal in SBR. The performance of the SBR system in the slaughterhouse wastewater treatment for combined carbon and nitrogen removal has been plotted in Figures 3, 4, and 5. The aerobic period was operated long enough (4.0 to 5.0 hours) to achieve nitrification to improve effluent quality. The presence of low DO $(2.4 \mathrm{mg} / \mathrm{L})$ level at the beginning of the aerobic react phase and subsequently increased progressively and reached to its maximum value at the end of the aeration period. The organic loading was decreased substantially at the beginning of anoxic period followed by a reduction in DO level. Generally, DO concentration, in the range of $2.4-4.5 \mathrm{mg} / \mathrm{L}$ prevailed in the reactor during the aerobic react period, which was beneficial for ammonium oxidation. The effluent $\mathrm{NH}_{4}{ }^{+}-\mathrm{N}$ was below $18.15 \mathrm{mg} / \mathrm{L}$, giving an average $\mathrm{NH}_{4}{ }^{+}-\mathrm{N}$ removal of $85.52 \%$ under $(4+4)$ hour react period combination. The effluent $\mathrm{NH}_{4}{ }^{+}-\mathrm{N}$ remained less than $13.28 \mathrm{mg} / \mathrm{L}$, yielding an average $\mathrm{NH}_{4}^{+}-\mathrm{N}$ removal of $88.78 \%$ under $(5+3)$ hour react period combination. Under $(5+4)$ hour react period combination, 
TABLE 2: Range of variables in ANN study.

\begin{tabular}{lcc}
\hline Serial number & Variables & Ranges \\
\hline 1 & Initial MLVSS concentration $(\mathrm{mg} / \mathrm{L})$ & $1810-2600$ \\
2 & Initial concentration of COD $(\mathrm{mg} / \mathrm{L})$ & $1910-2096$ \\
3 & Initial concentration of $\mathrm{NH}_{4}{ }^{+}-\mathrm{N}(\mathrm{mg} / \mathrm{L})$ & $112-130$ \\
4 & $\mathrm{pH}$ & $7.0-8.0$ \\
5 & Initial DO level (mg/L) & $2.4-4.5$ \\
6 & Total react time (hour) $_{7}$ & $8-9$ \\
7 & $\mathrm{COD} / \mathrm{NH}_{4}{ }^{+}-\mathrm{N}$ removal efficiency (\%) & $0-100$ \\
\hline
\end{tabular}

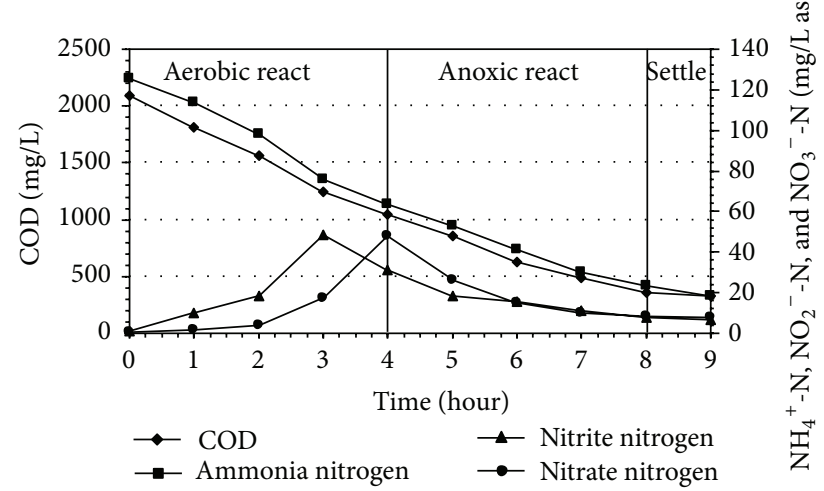

FIgURE 3: Carbon oxidation, nitrification, and denitrification profiles for slaughterhouse wastewater treatment in $(4+4)$ hour react cycle.

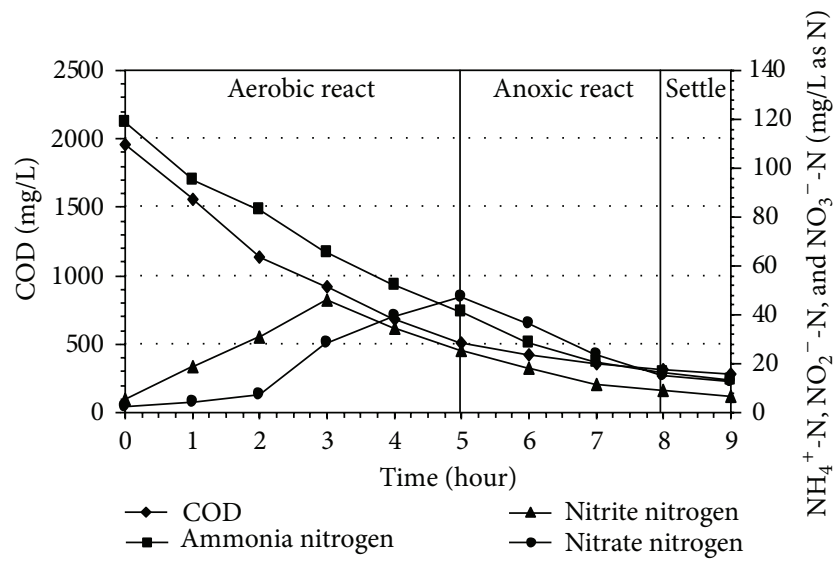

FIgURE 4: Carbon oxidation, nitrification, and denitrification profiles for slaughterhouse wastewater treatment in $(5+3)$ hour react cycle.

improved performance, in terms of $\mathrm{NH}_{4}{ }^{+}-\mathrm{N}$ oxidation, was observed that produced a final treated effluent having $\mathrm{NH}_{4}{ }^{+}-$ $\mathrm{N}$ concentration less than $12.55 \mathrm{mg} / \mathrm{L}$ as $\mathrm{N}$ indicating an average $90.28 \% \mathrm{NH}_{4}{ }^{+}-\mathrm{N}$ removal.

At the end of anoxic react period, under $(4+4)$ hour react period combination, $82.58 \%$ of nitrate reduction was achieved which descent noticeably to $67.65 \%$ under $(5+3)$

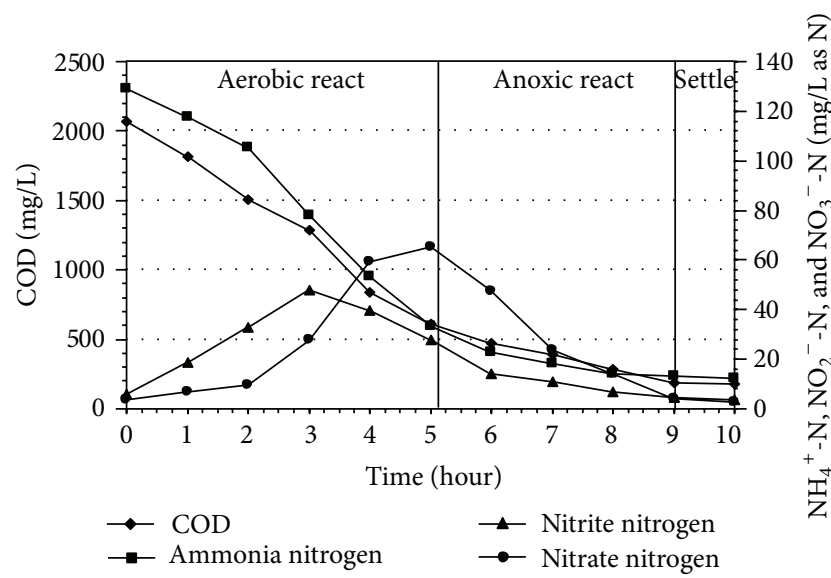

FIgURE 5: Carbon oxidation, nitrification, and denitrification profiles for slaughterhouse wastewater treatment in $(5+4)$ hour react cycle.

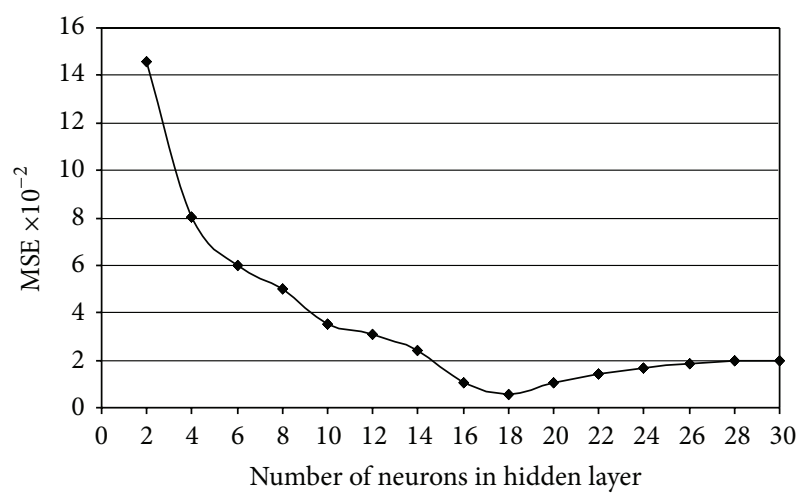

FIGURE 6: Relation between MSE and number of neurons in hidden layer.

hour react period combination due to nonavailability of sufficient anoxic reaction time. However, the nitrate reduction efficiency was found to be improved appreciably under $(5+4)$ hour react period in the extent of $93.62 \%$ yielding a nitrate concentration less than $4.18 \mathrm{mg} / \mathrm{L}$ as $\mathrm{N}$ at the end of anoxic react period from an initial nitrate level of approximately $65.43 \mathrm{mg} / \mathrm{L}$ as $\mathrm{N}$, present at the beginning of anoxic phase. It was interesting to observe that, by a marginal increment of 1-hour anoxic period, denitrification efficiency changes positively. In the present study, most of the nitrates were removed in the anoxic react phase. The amount of nitrate removal was as much as $82.58,67.65$ and $93.62 \%$ in $(4+4)$, $(5+3)$, and $(5+4)$ hour combination, respectively.

3.3. Development ANN Models for Combined Carbon Oxidation and Nitrification of Slaughterhouse Wastewater in SBR. Three models were developed for combined carbon oxidation and nitrification of slaughterhouse wastewater in the following combinations:

Model "A" (Combination-1): 4-hour aerobic and 4hour anoxic react period in SBR system; 
TABLE 3: Data set for ANN Model "A" under $(4+4)$ hour aerobic-anoxic react period.

\begin{tabular}{|c|c|c|c|c|c|c|c|c|}
\hline Serial number & $\begin{array}{c}\text { Initial } \\
\text { COD } \\
(\mathrm{mg} / \mathrm{L})\end{array}$ & $\begin{array}{c}\text { Initial } \\
\mathrm{NH}_{4}^{+}-\mathrm{N} \\
(\mathrm{mg} / \mathrm{L})\end{array}$ & Initial MLVSS (mg/L) & $\begin{array}{l}\text { Time } \\
\text { (hour) }\end{array}$ & $\mathrm{pH}$ & $\begin{array}{c}\text { Initial DO } \\
(\mathrm{mg} / \mathrm{L})\end{array}$ & $\begin{array}{l}\% \text { COD } \\
\text { removal } \\
\text { efficiency }\end{array}$ & $\begin{array}{c}\% \mathrm{NH}_{4}{ }^{+}-\mathrm{N} \\
\text { removal } \\
\text { efficiency }\end{array}$ \\
\hline 1 & 2004.25 & 112.41 & 2155.41 & 8 & 7.1 & 3.8 & 86.45 & 86.92 \\
\hline 2 & 2077.11 & 118.55 & 1844.22 & 8 & 7.4 & 2.4 & 88.11 & 88.52 \\
\hline 3 & 1922.64 & 117.34 & 1863.57 & 8 & 7.1 & 3.5 & 89.62 & 88.81 \\
\hline 4 & 1913.21 & 121.46 & 2482.36 & 8 & 7.0 & 2.7 & 85.37 & 84.44 \\
\hline 5 & 2030.25 & 117.52 & 2272.21 & 8 & 7.2 & 3.6 & 89.33 & 85.83 \\
\hline 6 & 1938.48 & 120.25 & 2212.54 & 8 & 7.0 & 3.7 & 83.21 & 85.11 \\
\hline 7 & 1925.41 & 124.36 & 2475.45 & 8 & 8.0 & 3.8 & 80.19 & 84.9 \\
\hline 8 & 2024.17 & 122.24 & 1940.26 & 8 & 7.0 & 4.4 & 86.08 & 85.25 \\
\hline 9 & 2094.40 & 113.84 & 2131.22 & 8 & 7.5 & 4.0 & 88.25 & 86.54 \\
\hline 10 & 2040.33 & 116.55 & 2075.35 & 8 & 7.0 & 2.8 & 88.65 & 82.97 \\
\hline 11 & 1998.34 & 125.52 & 2322.14 & 8 & 7.0 & 3.0 & 85.22 & 88.54 \\
\hline 12 & 1917.24 & 127.84 & 2391.22 & 8 & 7.2 & 3.0 & 85.39 & 89.31 \\
\hline 13 & 1989.17 & 128.66 & 1917.27 & 8 & 7.5 & 3.6 & 84.11 & 82.58 \\
\hline 14 & 1997.57 & 129.88 & 1968.26 & 8 & 8.0 & 3.5 & 86.05 & 90.31 \\
\hline 15 & 2085.27 & 124.24 & 2012.55 & 8 & 7.0 & 3.0 & 90.42 & 84.22 \\
\hline 16 & 2054.22 & 122.26 & 2048.22 & 8 & 7.4 & 3.0 & 91.94 & 86.27 \\
\hline 17 & 2014.11 & 122.31 & 2144.24 & 8 & 7.2 & 3.7 & 84.18 & 88.55 \\
\hline 18 & 1984.27 & 116.27 & 1950.25 & 8 & 7.1 & 3.8 & 84.62 & 89.33 \\
\hline 19 & 1932.92 & 127.57 & 1995.27 & 8 & 7.5 & 4.3 & 85.21 & 86.28 \\
\hline 20 & 2015.28 & 123.94 & 2212.51 & 8 & 7.5 & 4.4 & 85.22 & 82.85 \\
\hline 21 & 2008.15 & 122.27 & 2352.81 & 8 & 7.0 & 4.2 & 83.64 & 81.22 \\
\hline 22 & 2017.47 & 126.67 & 2432.55 & 8 & 7.6 & 4.0 & 88.52 & 81.6 \\
\hline 23 & 2037.81 & 120.76 & 2245.28 & 8 & 7.6 & 4.2 & 91.39 & 82.27 \\
\hline 24 & 1938.58 & 119.41 & 2185.35 & 8 & 7.4 & 3.6 & 85.35 & 85.22 \\
\hline 25 & 2096.55 & 125.22 & 2265.21 & 8 & 7.5 & 3.5 & 84.29 & 85.52 \\
\hline 26 & 2036.28 & 115.48 & 2258.36 & 8 & 7.1 & 3.4 & 86.55 & 87.22 \\
\hline 27 & 1965.25 & 114.88 & 2424.37 & 8 & 7.4 & 4.0 & 87.56 & 84.25 \\
\hline 28 & 1975.27 & 126.48 & 2575.36 & 8 & 7.0 & 2.9 & 86.34 & 87.54 \\
\hline 29 & 2072.55 & 128.85 & 1850.29 & 8 & 7.5 & 3.0 & 90.22 & 88.25 \\
\hline
\end{tabular}

Model "B" (Combination-2): 5-hour aerobic and 3hour anoxic react period in SBR system;

Model "C" (Combination-3): 5-hour aerobic and 4hour anoxic react period in SBR system.

The ANN model was developed for biological removal of combined organic carbon and nitrogen of a slaughterhouse wastewater in a sequencing batch reactor using experimental data. Table 2 represents the input parameters for developing the ANN studies. Total 29 experimental data sets were available for each aerobic/anoxic react period combination in SBR system. These data were divided into $50 \%$ for training set (15 data sets), $25 \%$ for validation set (7 data sets), and $25 \%$ for testing data set (7 data sets). The training set was used to develop the neural network. The validation data set was used to determine when the network's general performance was maximized through early stopping, and the testing data set was used to evaluate the generalization ability of the trained network. The 29 data sets used for development of ANN model in SBR system for each combination of aerobic/anoxic react period are presented in Tables 3,4 , and 5 .

During the training process, small weights were assigned to the connection between neurons in a random way. The weights were modified until the error between the predicted and experimental values of COD and ammonia nitrogen removal efficiency in SBR is minimized. The feedforward backpropagation (BP) algorithm with Levenberg-Marquardt 
TABLE 4: Data set for ANN Model "B" under $(5+3)$ hour aerobic-anoxic react period.

\begin{tabular}{|c|c|c|c|c|c|c|c|c|}
\hline Serial number & $\begin{array}{l}\text { Initial COD } \\
(\mathrm{mg} / \mathrm{L})\end{array}$ & $\begin{array}{c}\text { Initial } \\
\mathrm{NH}_{4}^{+}-\mathrm{N} \\
(\mathrm{mg} / \mathrm{L})\end{array}$ & $\begin{array}{l}\text { Initial } \\
\text { MLVSS } \\
(\mathrm{mg} / \mathrm{L})\end{array}$ & Time (hour) & $\mathrm{pH}$ & $\begin{array}{l}\text { Initial DO } \\
(\mathrm{mg} / \mathrm{L})\end{array}$ & $\begin{array}{l}\% \text { COD } \\
\text { removal } \\
\text { efficiency }\end{array}$ & $\begin{array}{c}\% \mathrm{NH}_{4}^{+}-\mathrm{N} \\
\text { removal efficiency }\end{array}$ \\
\hline 1 & 2044.23 & 113.01 & 2055.46 & 8 & 7.2 & 2.8 & 84.42 & 88.90 \\
\hline 2 & 2057.15 & 119.56 & 1944.22 & 8 & 7.5 & 3.4 & 84.16 & 86.55 \\
\hline 3 & 1972.65 & 118.32 & 1963.51 & 8 & 7.0 & 3.2 & 86.62 & 89.88 \\
\hline 4 & 1943.22 & 120.44 & 2382.33 & 8 & 7.5 & 2.9 & 82.35 & 86.45 \\
\hline 5 & 2050.22 & 116.50 & 2172.24 & 8 & 7.4 & 3.1 & 88.34 & 89.85 \\
\hline 6 & 1918.08 & 130.24 & 2412.52 & 8 & 7.5 & 3.5 & 84.26 & 87.15 \\
\hline 7 & 1955.47 & 121.35 & 2575.44 & 8 & 8.0 & 3.8 & 82.39 & 86.96 \\
\hline 8 & 2044.12 & 123.28 & 1940.22 & 8 & 7.5 & 4.0 & 85.58 & 88.24 \\
\hline 9 & 2084.00 & 117.81 & 2431.25 & 8 & 7.5 & 4.1 & 87.27 & 89.50 \\
\hline 10 & 2060.31 & 115.56 & 2275.32 & 8 & 7.0 & 2.6 & 86.66 & 88.95 \\
\hline 11 & 1948.35 & 124.50 & 2522.13 & 8 & 7.0 & 3.0 & 87.28 & 89.55 \\
\hline 12 & 1927.26 & 128.86 & 2491.21 & 8 & 7.3 & 3.8 & 82.30 & 89.30 \\
\hline 13 & 1979.14 & 127.64 & 2417.22 & 8 & 7.5 & 3.4 & 86.18 & 88.55 \\
\hline 14 & 1947.51 & 128.80 & 2568.21 & 8 & 8.0 & 3.5 & 86.85 & 91.35 \\
\hline 15 & 2075.26 & 120.25 & 2212.54 & 8 & 8.0 & 3.2 & 89.46 & 90.25 \\
\hline 16 & 2034.28 & 125.28 & 2148.25 & 8 & 7.6 & 3.0 & 90.93 & 91.22 \\
\hline 17 & 2024.15 & 125.36 & 2044.21 & 8 & 7.6 & 3.7 & 84.68 & 87.57 \\
\hline 18 & 1974.26 & 115.23 & 1850.24 & 8 & 7.2 & 3.6 & 84.62 & 88.37 \\
\hline 19 & 1922.92 & 126.50 & 1895.21 & 8 & 7.5 & 4.2 & 87.26 & 89.25 \\
\hline 20 & 2045.28 & 122.93 & 2412.52 & 8 & 7.0 & 4.5 & 87.25 & 86.80 \\
\hline 21 & 2088.15 & 112.20 & 2352.01 & 8 & 7.0 & 4.4 & 85.64 & 88.25 \\
\hline 22 & 2077.48 & 129.64 & 2132.55 & 8 & 7.8 & 4.0 & 89.53 & 91.60 \\
\hline 23 & 2057.84 & 122.36 & 2045.28 & 8 & 7.6 & 4.1 & 90.38 & 82.25 \\
\hline 24 & 1948.58 & 118.91 & 2085.33 & 8 & 7.0 & 3.4 & 84.37 & 86.26 \\
\hline 25 & 1962.45 & 118.55 & 2165.21 & 8 & 7.0 & 4.5 & 85.51 & 88.78 \\
\hline 26 & 2066.21 & 119.58 & 2158.32 & 8 & 7.6 & 3.8 & 87.50 & 89.28 \\
\hline 27 & 1925.24 & 124.68 & 2024.32 & 8 & 7.4 & 4.0 & 86.57 & 88.24 \\
\hline 28 & 1915.24 & 127.58 & 2175.33 & 8 & 7.0 & 2.8 & 85.33 & 88.50 \\
\hline 29 & 2042.54 & 129.85 & 1950.23 & 8 & 7.8 & 3.0 & 89.28 & 90.26 \\
\hline
\end{tabular}

(LM) training was applied for development of all three ANN models. The BP is an approximate steepest descent algorithm with MSE used as performance function. In the neural network development, different number of hidden layers, number of neurons in each layer, and type of transfer function for each neuron were analyzed with a learning rate of 1.0 and training goal of $10^{-5}$. Then, the trained networks were tested using the testing data sets and MSE method by modifying the network weights. It was found that network with one hidden layer of neurons was successful. The tansig transfer function was used in the hidden layer and linear transfer function in the output layer. The training of the network was carried out with different number of neurons in the hidden layer with training goal of $10^{-5}$. It is observed from Figure 6 that MSE value of 0.15584 is much higher for 2 neurons in one hidden layer. With the increase of neuron numbers in the hidden layer, there was a gradual decrease in MSE values attaining a minimum value of 0.00575 with 18 neurons in one hidden layer. With the further increase of hidden neurons, there was a sharp increase in MSE values. Hence, 18 hidden neurons were considered for optimization in the present study.

A regression analysis of the network response between the output and the corresponding target was also performed with 18 hidden neurons layer. Figures 7, 8, and 9 exhibit the training, validation, and test squared error for the LevenbergMarquardt algorithm for Model "A," "B," and "C," respectively, under three different combinations of aerobic-anoxic sequence, namely, $(4+4),(5+3)$, and $(5+4)$ hour of total 
TABLE 5: Data set for ANN Model "C" under $(5+4)$ hour aerobic-anoxic react period.

\begin{tabular}{|c|c|c|c|c|c|c|c|c|}
\hline $\begin{array}{l}\text { Serial } \\
\text { number }\end{array}$ & $\begin{array}{c}\text { Initial } \\
\text { COD } \\
(\mathrm{mg} / \mathrm{L})\end{array}$ & $\begin{array}{c}\text { Initial } \\
\mathrm{NH}_{4}^{+}-\mathrm{N} \\
(\mathrm{mg} / \mathrm{L})\end{array}$ & $\begin{array}{l}\text { Initial } \\
\text { MLVSS } \\
(\mathrm{mg} / \mathrm{L})\end{array}$ & $\begin{array}{l}\text { Time } \\
\text { (hour) }\end{array}$ & $\mathrm{pH}$ & $\begin{array}{c}\text { Initial DO } \\
(\mathrm{mg} / \mathrm{L})\end{array}$ & $\begin{array}{l}\text { \% COD } \\
\text { removal } \\
\text { efficiency }\end{array}$ & $\begin{array}{c}\mathrm{ONH}_{4}{ }^{+}-\mathrm{N} \\
\text { removal } \\
\text { efficiency }\end{array}$ \\
\hline 1 & 1914.23 & 115.65 & 2155.46 & 9 & 7.8 & 3.8 & 94.45 & 88.52 \\
\hline 2 & 2057.15 & 118.54 & 1844.22 & 9 & 8.0 & 4.4 & 90.11 & 89.82 \\
\hline 3 & 1982.65 & 124.36 & 1863.51 & 9 & 8.0 & 4.2 & 93.60 & 90.41 \\
\hline 4 & 1963.22 & 123.43 & 2282.33 & 9 & 7.0 & 3.9 & 95.37 & 90.64 \\
\hline 5 & 2050.22 & 121.55 & 2072.24 & 9 & 7.0 & 4.1 & 90.33 & 87.73 \\
\hline 6 & 1978.08 & 122.21 & 2212.52 & 9 & 7.2 & 4.5 & 93.21 & 91.21 \\
\hline 7 & 1965.47 & 120.33 & 2475.44 & 9 & 7.6 & 3.8 & 90.19 & 88.93 \\
\hline 8 & 2044.12 & 124.26 & 1840.22 & 9 & 7.2 & 3.0 & 92.08 & 88.35 \\
\hline 9 & 2084.00 & 127.88 & 2331.25 & 9 & 7.7 & 3.1 & 89.25 & 87.44 \\
\hline 10 & 2070.31 & 117.54 & 2175.32 & 9 & 7.1 & 3.6 & 89.65 & 86.45 \\
\hline 11 & 1978.35 & 120.56 & 2422.13 & 9 & 7.4 & 4.0 & 95.22 & 92.54 \\
\hline 12 & 1967.26 & 124.87 & 2591.21 & 9 & 7.5 & 2.8 & 95.39 & 91.33 \\
\hline 13 & 1949.14 & 124.67 & 2517.22 & 9 & 7.8 & 4.4 & 94.11 & 92.48 \\
\hline 14 & 1977.51 & 125.82 & 2068.21 & 9 & 8.0 & 4.5 & 93.05 & 90.61 \\
\hline 15 & 2075.26 & 119.26 & 2112.54 & 9 & 8.0 & 4.2 & 92.42 & 89.62 \\
\hline 16 & 2034.28 & 124.29 & 2248.25 & 9 & 7.6 & 4.0 & 94.94 & 89.77 \\
\hline 17 & 2044.15 & 123.34 & 2244.21 & 9 & 7.7 & 2.7 & 94.18 & 87.65 \\
\hline 18 & 2084.26 & 125.26 & 1950.24 & 9 & 7.6 & 3.6 & 94.62 & 90.43 \\
\hline 19 & 2032.92 & 128.52 & 1895.21 & 9 & 7.6 & 3.2 & 95.21 & 91.88 \\
\hline 20 & 2045.28 & 129.92 & 2112.52 & 9 & 7.2 & 3.5 & 95.22 & 92.95 \\
\hline 21 & 2078.15 & 116.26 & 2052.01 & 9 & 7.2 & 3.4 & 93.64 & 88.22 \\
\hline 22 & 2057.48 & 126.66 & 2332.55 & 9 & 7.9 & 3.0 & 89.52 & 86.65 \\
\hline 23 & 2027.84 & 123.34 & 2545.28 & 9 & 7.5 & 3.1 & 92.39 & 89.24 \\
\hline 24 & 1948.58 & 119.94 & 1985.33 & 9 & 7.5 & 4.4 & 95.35 & 91.54 \\
\hline 25 & 2065.25 & 128.92 & 2365.21 & 9 & 7.0 & 4.0 & 91.36 & 90.28 \\
\hline 26 & 2066.21 & 118.53 & 1958.32 & 9 & 7.3 & 4.2 & 90.55 & 85.32 \\
\hline 27 & 1945.24 & 124.61 & 1824.32 & 9 & 7.0 & 3.0 & 92.56 & 89.45 \\
\hline 28 & 1955.24 & 126.56 & 2275.33 & 9 & 8.0 & 3.8 & 88.34 & 85.64 \\
\hline 29 & 2022.54 & 122.80 & 2550.23 & 9 & 8.0 & 4.0 & 91.22 & 89.65 \\
\hline
\end{tabular}

react period. It was observed that Models "A," "B," and "C" took 7, 6, and 5 epochs, respectively, for training, validation, and testing of 29 data sets in each model. Finally, an optimal three-layered ANN with tangent sigmoid transfer function (tansig) at hidden layer with 18 neurons and linear transfer function (purelin) at output layer with Levenberg-Marquardt (LM) training algorithm was chosen to predict the COD and ammonia nitrogen removal efficiency in Models "A," "B," and "C," respectively.

The scattered diagrams of linear regression analysis for three model were plotted in Figures 10 and 11 for Model "A," Figures 12 and 13 for Model "B," and Figures 14 and 15 for Model "C" in correspondence with comparison between experimental and ANN predicted values of COD and $\mathrm{NH}_{4}{ }^{+}-$ $\mathrm{N}$ removal efficiencies of each models, respectively. The two lines were used to show the success of the prediction. The one is the perfect fit line (predicted data equal to experimental data), on which all the data of an ideal model are lying. Another line corresponds to best fits to scatter plot for chaotic data with equation $Y=m x+c$ that is obtained with regression analysis based on the minimization of the squared errors. The plotting of the results as obtained through ANN exercise using the experimental data satisfactorily predicted the success of the experimental data and validated the model. The values of coefficient of determination $(R)$ above 0.90 with slope approaching 1 and $Y$ intercept value closer to zero were 


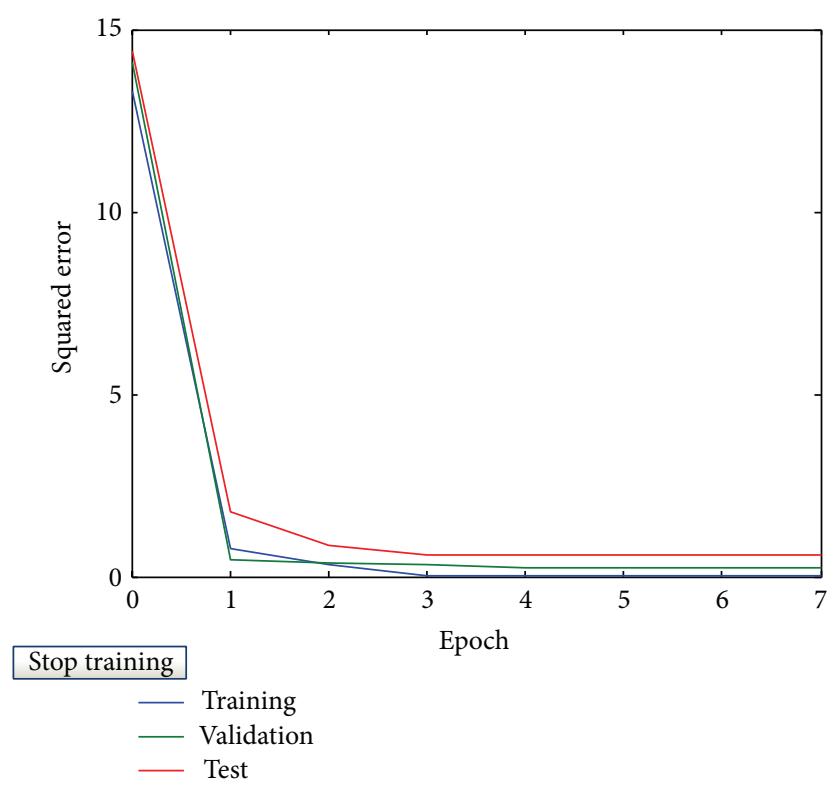

FIGURE 7: ANN Model "A" training, validation, and test squared error for the Levenberg-Marquardt algorithm for prediction of COD and $\mathrm{NH}_{4}{ }^{+}-\mathrm{N}$ removal efficiency during $(4+4)$ aerobic-anoxic react period combination in SBR system.

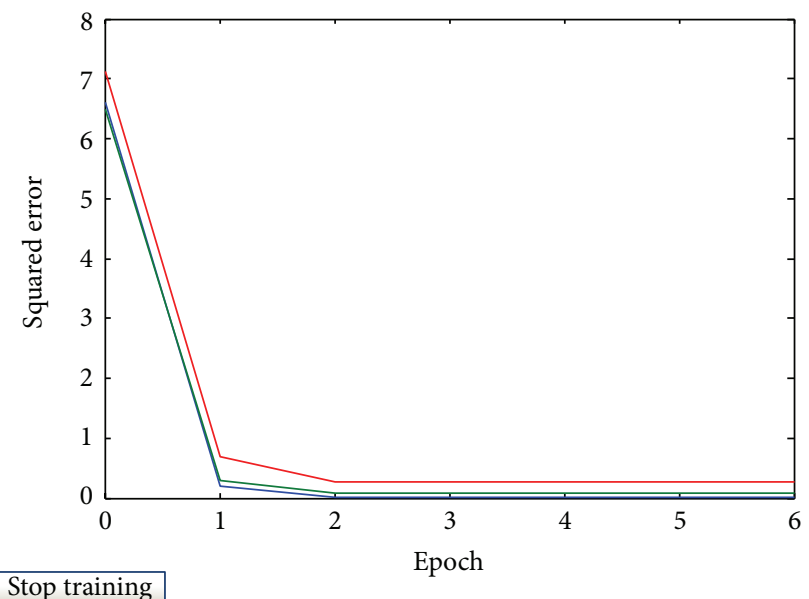

Stop training

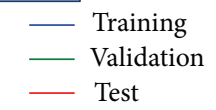

Figure 8: ANN Model “B” training, validation, and test squared error for the Levenberg-Marquardt algorithm for prediction of COD and $\mathrm{NH}_{4}{ }^{+}-\mathrm{N}$ removal efficiency during $(5+3)$ aerobic-anoxic react period combination in SBR system.

achieved through results of statistical analysis for removal of $\mathrm{COD}$ and $\mathrm{NH}_{4}^{+}-\mathrm{N}$ in SBR.

The coefficient of determination is also presented as $R$. The values of coefficient of determination $(R)$ for COD and $\mathrm{NH}_{4}{ }^{+}-\mathrm{N}$ removal are found to be 0.947 and 0.960 , respectively, which indicate a reasonable fitting to experimental data. Smith [25] suggested the following values of coefficient

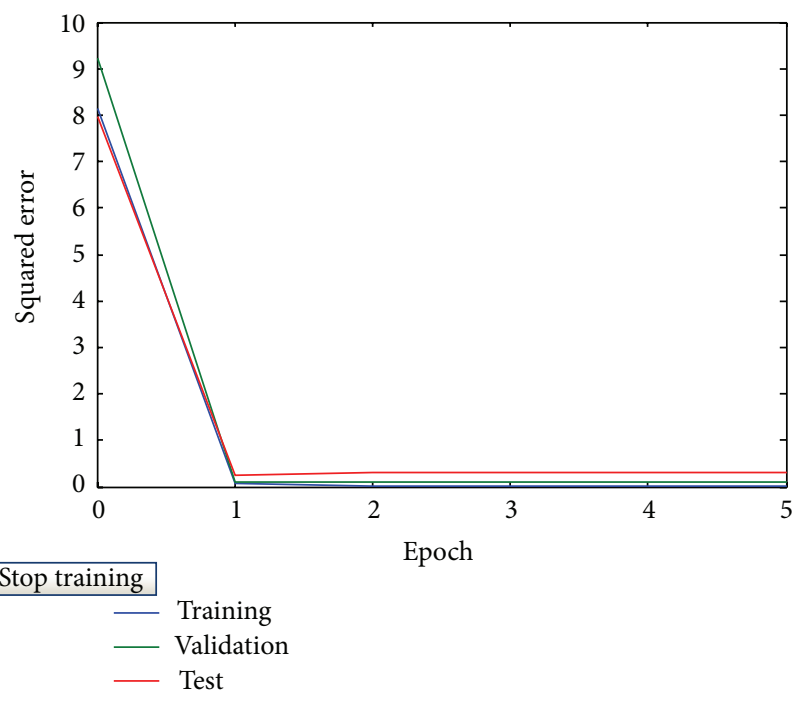

Figure 9: ANN Model "C" training, validation, and test squared error for the Levenberg-Marquardt algorithm for prediction of COD and $\mathrm{NH}_{4}{ }^{+}-\mathrm{N}$ removal efficiency during $(5+4)$ aerobic-anoxic react period combination in SBR system.

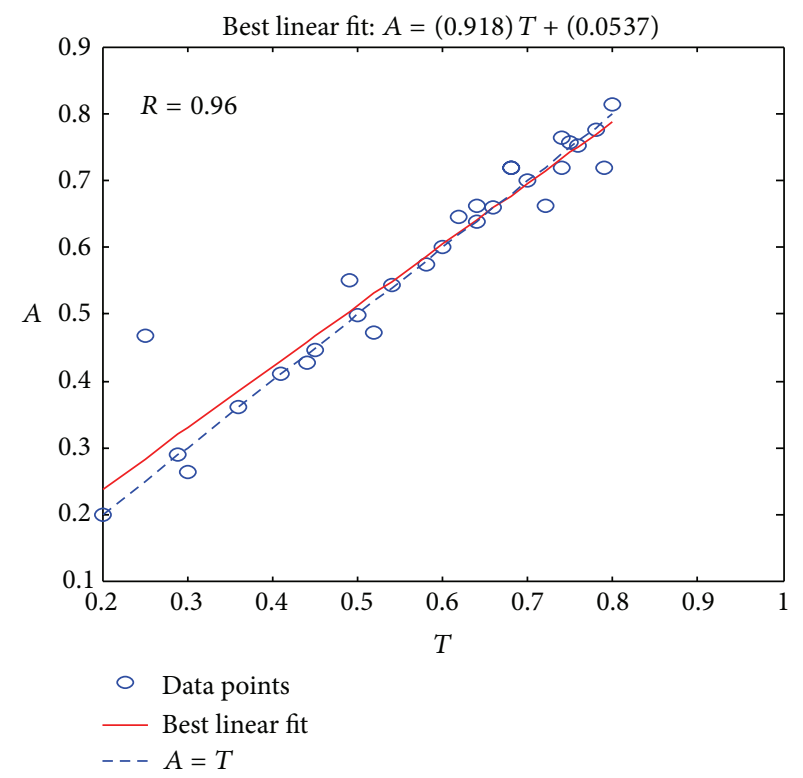

FIGURE 10: Linear regression analysis of ANN Model "A" for COD removal efficiency during $(4+4)$ aerobic-anoxic react period combination in SBR system (A: simulated values, $T$ : experimental values).

of determination $(R)$ between 0.0 and 1.0 for different sets of variable:

$R \geq 0.8$ strong correlation exists between two sets of variables;

$0.2 \leq R \leq 0.8$ correlations exist between the two sets of variables;

$R \leq 0.2$ weak correlation exists between the two sets of variables. 


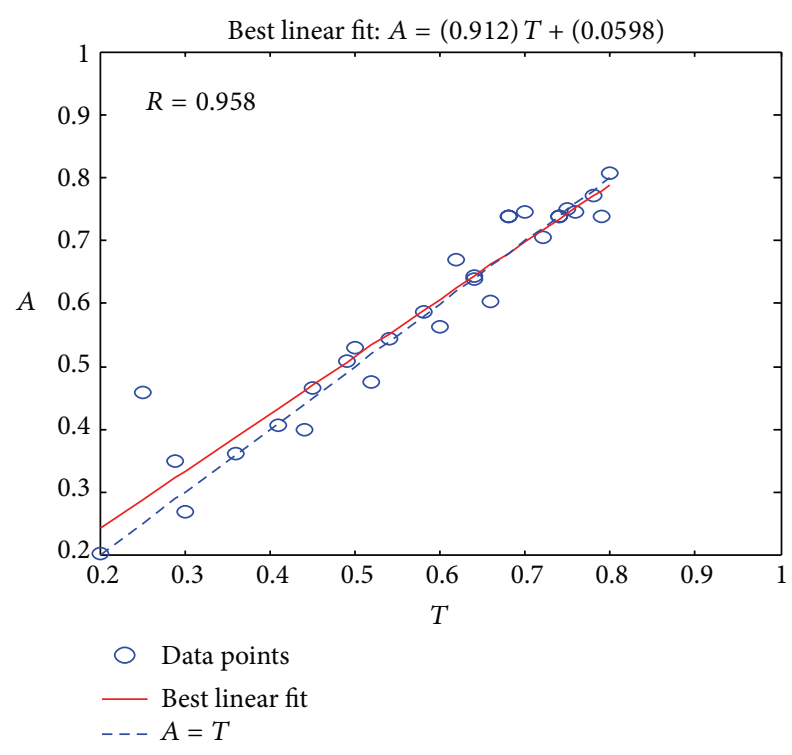

FIGURE 11: Linear regression analysis of ANN Model "A" for $\mathrm{NH}_{4}{ }^{+}$$\mathrm{N}$ removal efficiency during $(4+4)$ aerobic-anoxic react period combination in SBR system ( $A$ : simulated values, $T$ : experimental values).

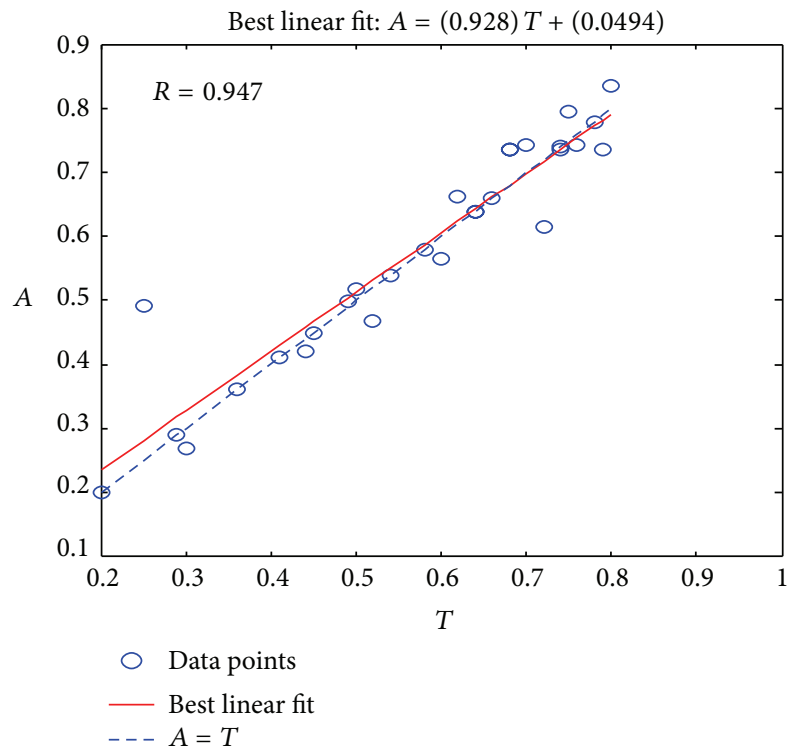

FIGURE 12: Linear regression analysis of ANN Model "B" for COD removal efficiency during $(5+3)$ aerobic-anoxic react period combination in SBR system (A: simulated values, $T$ : experimental values).

The linear regression between the network outputs and the corresponding targets showed that the neural network outputs (forecasted data) were obviously agreed with the experimental values. The correlation between ANN testing outputs and the experimental values of COD and $\mathrm{NH}_{4}{ }^{+}-\mathrm{N}$ removal efficiency for all test data (7 data sets) of Models "A,"

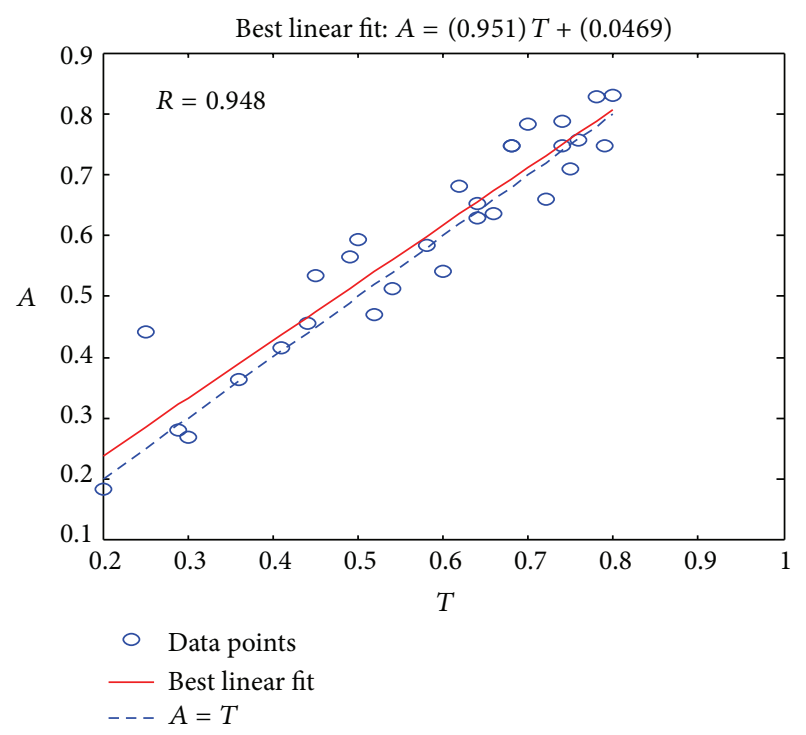

FIGURE 13: Linear regression analysis of ANN Model "B" for $\mathrm{NH}_{4}{ }^{+}$$\mathrm{N}$ removal efficiency during $(5+3)$ aerobic-anoxic react period combination in SBR system ( $A$ : simulated values, $T$ : experimental values).

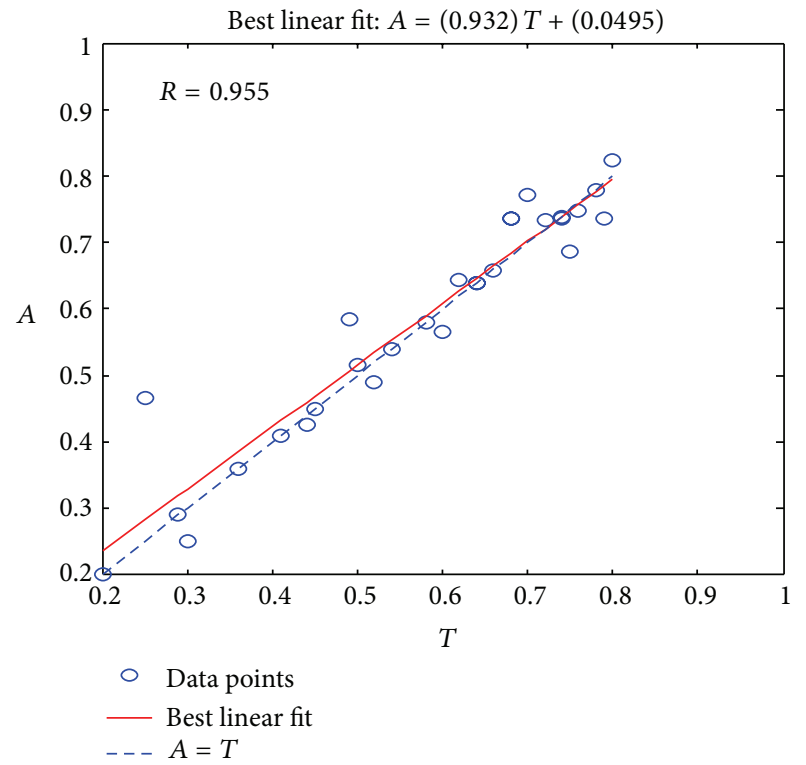

FIgURE 14: Linear regression analysis of ANN Model "C" for COD removal efficiency during $(5+4)$ aerobic-anoxic react period combination in SBR system (A: simulated values, $T$ : experimental values).

"B," and "C" are shown in Figures 16, 17, and 18, respectively. This results are reasonable, since the experimental and ANN model predicted data set error has similar characteristics, and it does not show that any significant change over fitting has occurred. Comparison of the ANN model's results and experimental results of $\mathrm{COD}$ and $\mathrm{NH}_{4}{ }^{+}-\mathrm{N}$ removal 


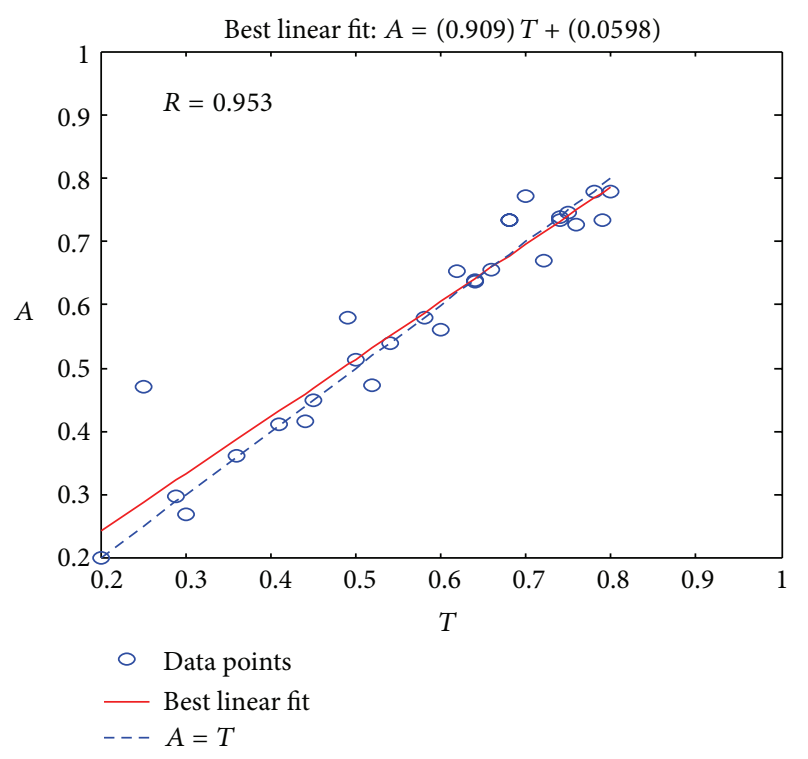

FIGURE 15: Linear regression analysis of ANN Model "C" for $\mathrm{NH}_{4}{ }^{+}$$\mathrm{N}$ removal efficiency during $(5+4)$ aerobic-anoxic react period combination in SBR system (A: simulated values, $T$ : experimental values).

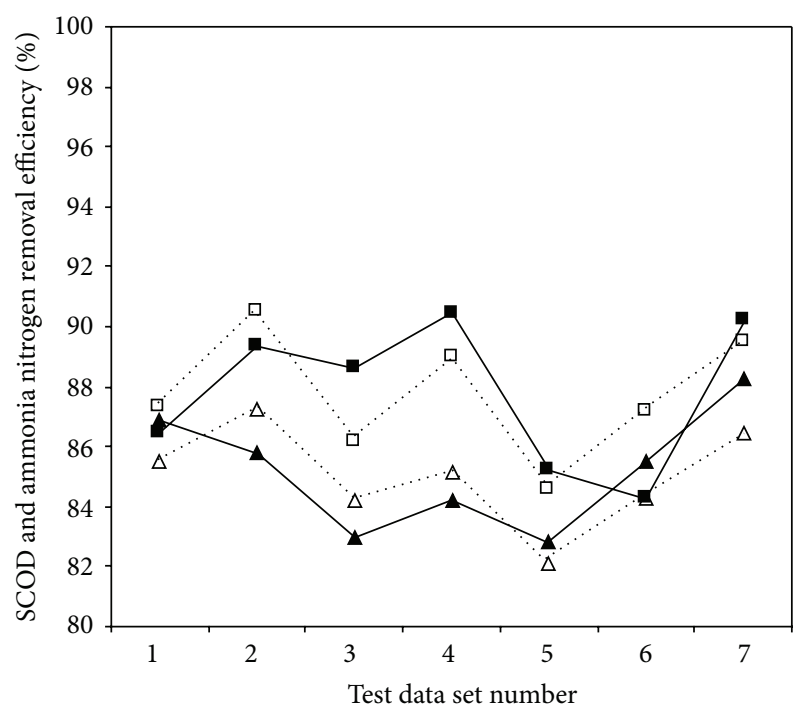

- Experimental values of SCOD removal efficiency

..๑.. ANN predicted values of SCOD removal efficiency

$\neg$ Experimental values of ammonia nitrogen removal efficiency

- $\triangle$ ANN predicted values of ammonia nitrogen removal efficiency

FIGURE 16: Stimulation results of Model "A" for test data sets.

efficiencies for all test data of Models "A," "B," and "C" are presented in Tables 6, 7, and 8 , respectively. The performance error of experimental and ANN model predicted values for COD and $\mathrm{NH}_{4}{ }^{+}-\mathrm{N}$ removal efficiency in SBR is visualized within limit of $4 \%$. The statistical analysis of the results of the

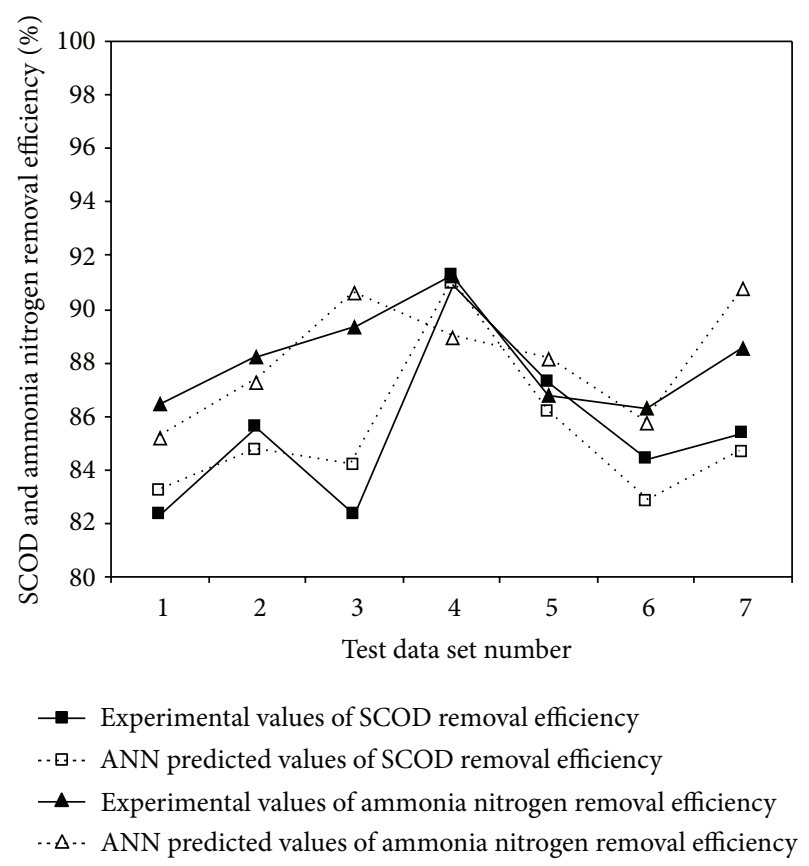

FIGURE 17: Stimulation results of Model "B" for test data sets.

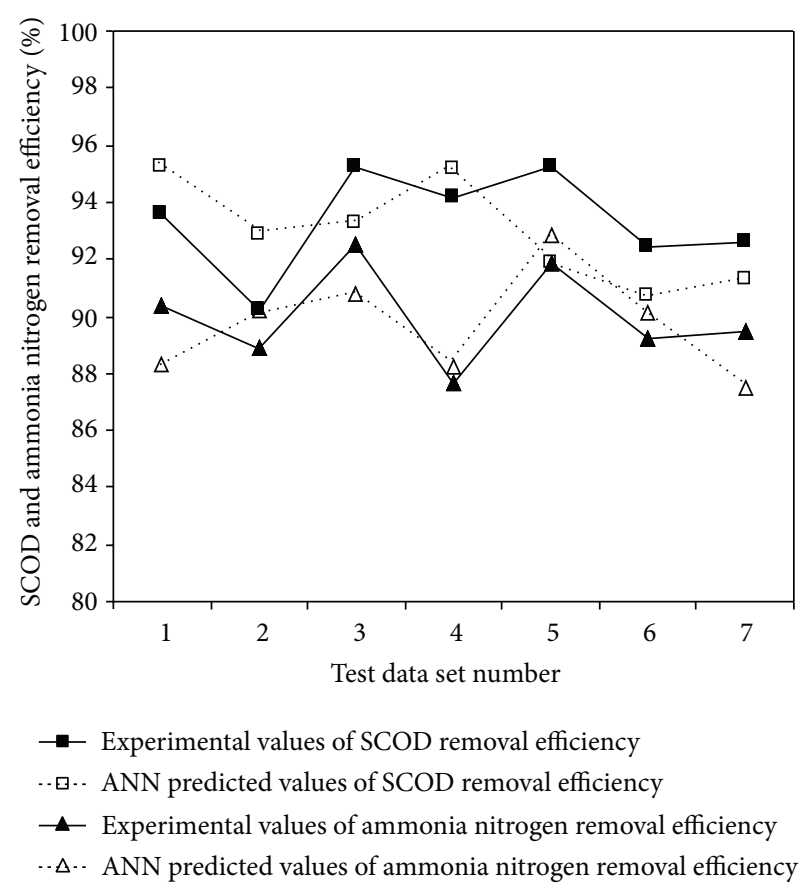

FIGURE 18: Stimulation results of Model "C" for test data sets.

network performance is presented in Table 9. The values of ME, MSE, and RMSE of all three models for COD and $\mathrm{NH}_{4}{ }^{+}$$\mathrm{N}$ removal efficiency are on lower side range. It was found that the predicted values of $\mathrm{COD}$ and $\mathrm{NH}_{4}{ }^{+}$-N removal efficiency by ANN model are very close to the experimental values for all data sets in test series of Models "A," "B," and "C." 
TABLE 6: Comparison of ANN Model "A" output and experimental values for test data set.

\begin{tabular}{lcccccc}
\hline \multirow{2}{*}{ Serial number } & \multicolumn{2}{c}{ COD removal efficiency (\%) } & \multicolumn{2}{c}{$\mathrm{NH}_{4}{ }^{+}-\mathrm{N}$ removal efficiency (\%) } & \multicolumn{2}{c}{ Error (\%) } \\
& Experimental values & ANN predicted values & Experimental values & ANN predicted values & COD & $\mathrm{NH}_{4}{ }^{+}-\mathrm{N}^{2}$ \\
\hline 1 & 86.45 & 87.32 & 86.92 & 85.54 & -0.87 & 1.38 \\
2 & 89.33 & 90.52 & 85.83 & 87.22 & -1.19 & -1.39 \\
3 & 88.65 & 86.15 & 82.97 & 84.19 & 2.50 & -1.22 \\
4 & 90.42 & 88.95 & 84.22 & 85.12 & 1.47 & -0.90 \\
5 & 85.22 & 84.55 & 82.85 & 82.12 & 0.67 & 0.73 \\
6 & 84.29 & 87.15 & 85.52 & 84.28 & -2.86 & 1.24 \\
7 & 90.22 & 89.51 & 88.25 & 86.45 & 0.71 & 1.80 \\
\hline
\end{tabular}

TABLE 7: Comparison of ANN Model “B” output and experimental values for test data set.

\begin{tabular}{lcccccc}
\hline \multirow{2}{*}{ Serial number } & \multicolumn{2}{c}{ COD removal efficiency (\%) } & \multicolumn{2}{c}{$\mathrm{NH}_{4}{ }^{+}$-N removal efficiency (\%) } & \multicolumn{2}{c}{ Error (\%) } \\
& Experimental values & ANN predicted values & Experimental values & ANN predicted values & $\mathrm{COD}^{-}$ & $\mathrm{NH}_{4}{ }^{+}-\mathrm{N}^{-}$ \\
\hline 1 & 82.35 & 83.18 & 86.45 & 85.15 & -0.83 & 1.30 \\
2 & 85.58 & 84.72 & 88.24 & 87.27 & 0.86 & 0.97 \\
3 & 82.30 & 84.15 & 89.30 & 90.56 & -1.85 & -1.26 \\
4 & 90.93 & 91.25 & 91.22 & 88.95 & -0.32 & 2.27 \\
5 & 87.25 & 86.12 & 86.80 & 88.16 & 1.13 & -1.36 \\
6 & 84.37 & 82.78 & 86.26 & 85.75 & 1.59 & 0.51 \\
7 & 85.33 & 84.62 & 88.50 & 90.78 & 0.71 & -2.28 \\
\hline
\end{tabular}

TABLE 8: Comparison of ANN Model "C" output and experimental values for test data set.

\begin{tabular}{lcccccc}
\hline \multirow{2}{*}{ Serial number } & \multicolumn{2}{c}{ COD removal efficiency (\%) } & \multicolumn{2}{c}{$\mathrm{NH}_{4}{ }^{+}$-N removal efficiency (\%) } & \multicolumn{2}{c}{ Error (\%) } \\
& Experimental values & ANN predicted values & Experimental values & ANN predicted values & COD & $\mathrm{NH}_{4}{ }^{+}-\mathrm{N}$ \\
\hline 1 & 93.60 & 95.24 & 90.41 & 88.35 & -1.64 & 2.06 \\
2 & 90.19 & 92.85 & 88.93 & 90.18 & -2.66 & -1.25 \\
3 & 95.22 & 93.28 & 92.54 & 90.76 & 1.94 & 1.78 \\
4 & 94.18 & 95.15 & 87.65 & 88.25 & -0.97 & -0.60 \\
5 & 95.21 & 91.88 & 91.88 & 92.85 & 3.33 & -0.97 \\
6 & 92.39 & 90.74 & 89.24 & 90.12 & 1.65 & -0.88 \\
7 & 92.56 & 91.25 & 89.45 & 87.48 & 1.31 \\
\hline
\end{tabular}

TABLE 9: Comparison of performance statistics of three ANN models.

\begin{tabular}{|c|c|c|c|c|c|c|c|}
\hline Model number & $\begin{array}{l}\text { Pollutant } \\
\text { removal } \\
\text { efficiency }\end{array}$ & $\mathrm{ME}$ & MSE & RMSE & $\begin{array}{l}\text { Coefficient of } \\
\text { determination }\end{array}$ & Slope & $\begin{array}{c}Y \text {-axis } \\
\text { intercept }\end{array}$ \\
\hline Model "A" & $\begin{array}{l}\text { COD removal } \\
\mathrm{NH}_{4}^{+}-\mathrm{N} \\
\text { removal }\end{array}$ & $\begin{array}{l}0.06 \\
0.23\end{array}$ & $\begin{array}{l}2.81 \\
1.63\end{array}$ & $\begin{array}{l}1.67 \\
1.27\end{array}$ & $\begin{array}{l}0.960 \\
0.958\end{array}$ & $\begin{array}{l}0.918 \\
0.912\end{array}$ & $\begin{array}{l}0.0537 \\
0.0598\end{array}$ \\
\hline Model "B" & $\begin{array}{c}\text { COD removal } \\
\mathrm{NH}_{4}^{+}-\mathrm{N} \\
\text { removal }\end{array}$ & $\begin{array}{l}0.18 \\
0.02\end{array}$ & $\begin{array}{l}1.32 \\
2.38\end{array}$ & $\begin{array}{l}1.14 \\
1.54\end{array}$ & $\begin{array}{l}0.947 \\
0.948\end{array}$ & $\begin{array}{l}0.928 \\
0.951\end{array}$ & $\begin{array}{l}0.0494 \\
0.0469\end{array}$ \\
\hline Model "C" & $\begin{array}{l}\text { COD removal } \\
\mathrm{NH}_{4}^{+}-\mathrm{N} \\
\text { removal }\end{array}$ & $\begin{array}{l}0.42 \\
0.30\end{array}$ & $\begin{array}{l}4.28 \\
2.13\end{array}$ & $\begin{array}{l}2.06 \\
1.45\end{array}$ & $\begin{array}{l}0.955 \\
0.953\end{array}$ & $\begin{array}{l}0.932 \\
0.909\end{array}$ & $\begin{array}{l}0.0495 \\
0.0598\end{array}$ \\
\hline
\end{tabular}




\section{Conclusions}

Based on performing all relevant experiment and analysis of results, it is concluded that SBR is a reasonable alternative option for simultaneous removal of high COD and $\mathrm{NH}_{4}{ }^{+}-\mathrm{N}$ containing wastewater that finds slaughterhouse effluent with others. The experimental values indicated that both COD and $\mathrm{NH}_{4}{ }^{+}-\mathrm{N}$ could effectively be treated by heterotrophic facultative bacteria. It was found that under aerobic condition, maximum removal efficiency of about $95.57 \%$ of COD and 92.95\% $\mathrm{NH}_{4}{ }^{+}-\mathrm{N}$ could be achieved over a react period of 9 hours for pretreated slaughterhouse wastewater in SBR. The combination of 5.0-hour aerobic react period and 4.0-hour anoxic react period is found to be reasonable from the view point of both organic carbon oxidation and nitrogen removal aspects. A steady increase in MLVSS level has been occurred during experiment. The overall increase in MLVSS in both the phases demonstrated the favourable microbial activity for organic carbon oxidation, nitrification, and denitrification.

The three neural network Models "A," "B," and " $\mathrm{C}$ " under three different combinations of aerobic-anoxic sequence, namely, $(4+4),(5+3)$, and $(5+4)$ hour of total react period, were successfully trained and tested which could forecast pollutant removal efficiency for combined carbon oxidation and nitrification of slaughterhouse wastewater in SBR. Based on the results obtained from the ANNs trained and limited to the architecture of the ANNs that had been trained, it is found that the ANN-based models can provide an efficient and a robust tool in predicting SBR performance. It was also found that after training, three ANN-based models were able to generalize very well when tested against any unknown data set. This observation yielded that the ANN-based models can be identified without detailed information of the kinetics of the system. In other words, as compared to statistical methods, ANNs can provide a more general framework for determining relationships between data and do not require specification of any functional form. Based on experimental results, the error of ANN model output was well within 3.33\% and also the coefficient of determination $(R)$ above 0.94 and slope approaching 1 with $Y$ intercept value closer to zero. The study also indicated that the ANN model technique has a great potential in prediction of organic carbon and nutrients removal efficiency in biological system.

\section{Conflict of Interests}

The authors disclosed the fact that this paper has been prepared for academic purpose for research persuasion and exchange of knowledge. There is no bearing on any financial relation with any commercial identities and also avoiding any conflict of interests.

\section{Acknowledgment}

This study was supported by the research funds of Jadavpur University, Jadavpur, Kolkata-32.

\section{References}

[1] Metcalf and Eddy, Wastewater Engineering-Treatment, Disposal and Reuse, Tata McGraw-Hill, New York, NY, USA, 4th edition, 1995.

[2] J. Grady, G. Daigger, and H. Lim, Biological Wastewater Treatment, Marcel Dekker, New York, NY, USA, 1999.

[3] N. Bhat and T. J. McAvoy, "Use of neural nets for dynamic modeling and control of chemical process systems," Computers and Chemical Engineering, vol. 14, no. 4-5, pp. 573-582, 1990.

[4] M.-J. Syu and G. T. Tsao, "Neural network modeling of batch cell growth pattern," Biotechnology and Bioengineering, vol. 42, no. 3, pp. 376-380, 1993.

[5] M. J. Willis, C. Di Massimo, G. A. Montague, M. T. Tham, and A. J. Morris, "Artificial neural networks in process engineering," IEE Proceedings D, vol. 138, no. 3, pp. 256-266, 1991.

[6] G. A. Montague, A. J. Morris, and M. T. Tham, "Enhancing bioprocess operability with generic software sensors," Journal of Biotechnology, vol. 25, no. 1-2, pp. 183-201, 1992.

[7] S. Linko, J. Luopa, and Y.-H. Zhu, "Neural networks as "software sensors" in enzyme production," Journal of Biotechnology, vol. 52, no. 3, pp. 257-266, 1997.

[8] M. M. Hamed, M. G. Khalafallah, and E. A. Hassanien, "Prediction of wastewater treatment plant performance using artificial neural networks," Environmental Modelling and Software, vol. 19, no. 10, pp. 919-928, 2004.

[9] D. Aguado, A. Ferrer, A. Seco, and J. Ferrer, "Comparison of different predictive models for nutrient estimation in a sequencing batch reactor for wastewater treatment," Chemometrics and Intelligent Laboratory Systems, vol. 84, no. 1-2, pp. 75-81, 2006.

[10] M. Häck and M. Köhne, "Estimation of wastewater process parameters using neural networks," Water Science and Technology, vol. 33, no. 1, pp. 101-115, 1996.

[11] M. Bongards, "Improving the efficiency of a wastewater treatment plant by fuzzy control and neural networks," Water Science and Technology, vol. 43, no. 11, pp. 189-196, 2001.

[12] Y.-S. T. Hong, M. R. Rosen, and R. Bhamidimarri, "Analysis of a municipal wastewater treatment plant using a neural networkbased pattern analysis," Water Research, vol. 37, no. 7, pp. 16081618, 2003.

[13] W. C. Chen, N.-B. Chang, and J.-C. Chen, "Rough set-based hybrid fuzzy-neural controller design for industrial wastewater treatment," Water Research, vol. 37, no. 1, pp. 95-107, 2003.

[14] S. Eslamian and N. Lavaei, "Modelling nitrate pollution of groundwater using artificial neural network and genetic algorithm in an arid zone," International Journal of Water, vol. 5, no. 2, pp. 194-203, 2009.

[15] H. Zhao, O. J. Hao, T. J. McAvoy, and C.-H. Chang, "Modeling nutrient dynamics in sequencing batch reactor," Journal of Environmental Engineering, vol. 123, no. 4, pp. 311-318, 1997.

[16] N. Al-Mutairi, N. Kartam, P. Koushki, and M. Al-Mutairi, "Modeling and predicting biological performance of contact stabilization process using artificial neural networks," Journal of Computing in Civil Engineering, vol. 18, no. 4, pp. 341-349, 2004.

[17] M. N. Kashani and S. Shahhosseini, "A methodology for modeling batch reactors using generalized dynamic neural networks," Chemical Engineering Journal, vol. 159, no. 1-3, pp. 195-202, 2010.

[18] L. Luccarini, G. L. Bragadin, G. Colombini et al., "Formal verification of wastewater treatment processes using events detected from continuous signals by means of artificial neural networks. Case study: SBR plant," Environmental Modelling and Software, vol. 25, no. 5, pp. 648-660, 2010. 
[19] American Public Health Association, American Water Works Association, Water Pollution Control Federation, Standard Methods for the Examination of Water and Wastewater, Washington, DC, USA, 20th edition, 1998.

[20] A. Tremblay, R. D. Tyagi, and R. Y. Surampalli, "Effect of SRT on nutrient removal in SBR system," Practice Periodical of Hazardous, Toxic, and Radioactive Waste Management, vol. 3, no. 4, pp. 183-190, 1999.

[21] H. Zhao, O. J. Hao, T. J. McAvoy, and C.-H. Chang, "Modeling nutrient dynamics in sequencing batch reactor," Journal of Environmental Engineering, vol. 123, no. 4, pp. 311-318, 1997.

[22] M. Cote, B. P. A. Grandjean, P. Lessard, and J. Thibault, "Dynamic modelling of the activated sludge process: improving prediction using neural networks," Water Research, vol. 29, no. 4, pp. 995-1004, 1995.

[23] R. M. Aghav, S. Kumar, and S. N. Mukherjee, "Artificial neural network modeling in competitive adsorption of phenol and resorcinol from water environment using some carbonaceous adsorbents," Journal of Hazardous Materials, vol. 188, no. 1-3, pp. 67-77, 2011.

[24] B. B. Ekici and U. T. Aksoy, "Prediction of building energy consumption by using artificial neural networks," Advances in Engineering Software, vol. 40, no. 5, pp. 356-362, 2009.

[25] G. N. Smith, Probability and Statistics in Civil Engineering: An Introduction, Collins, London, UK, 1986. 

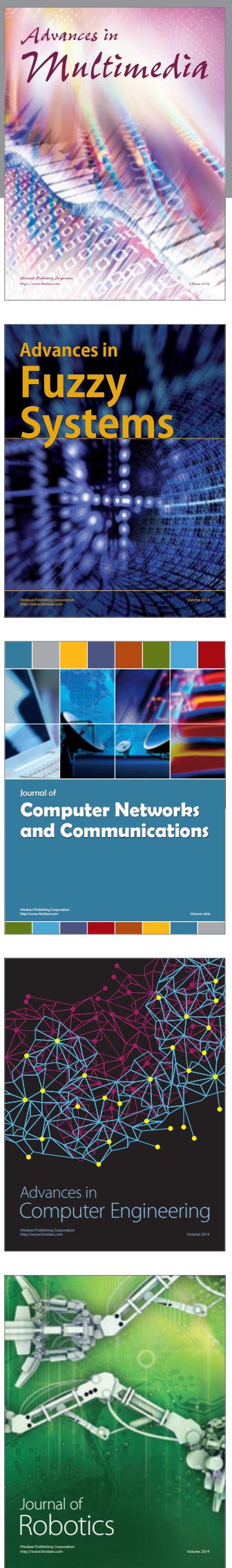

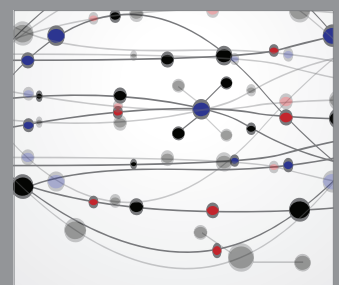

The Scientific World Journal
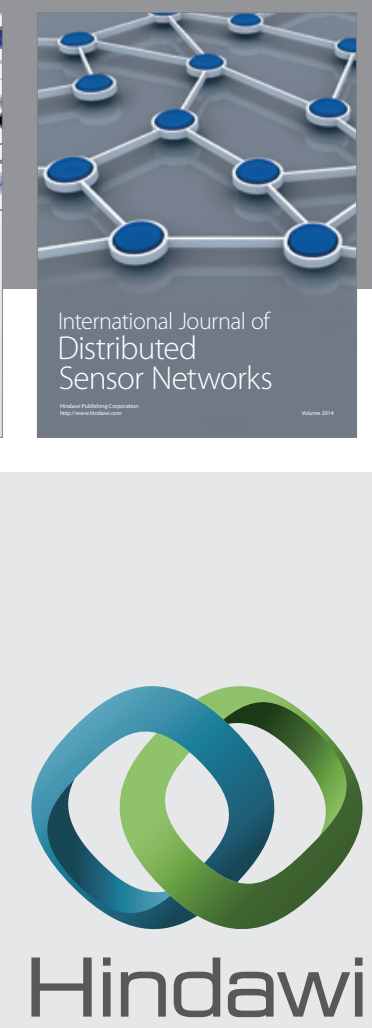

Submit your manuscripts at

http://www.hindawi.com
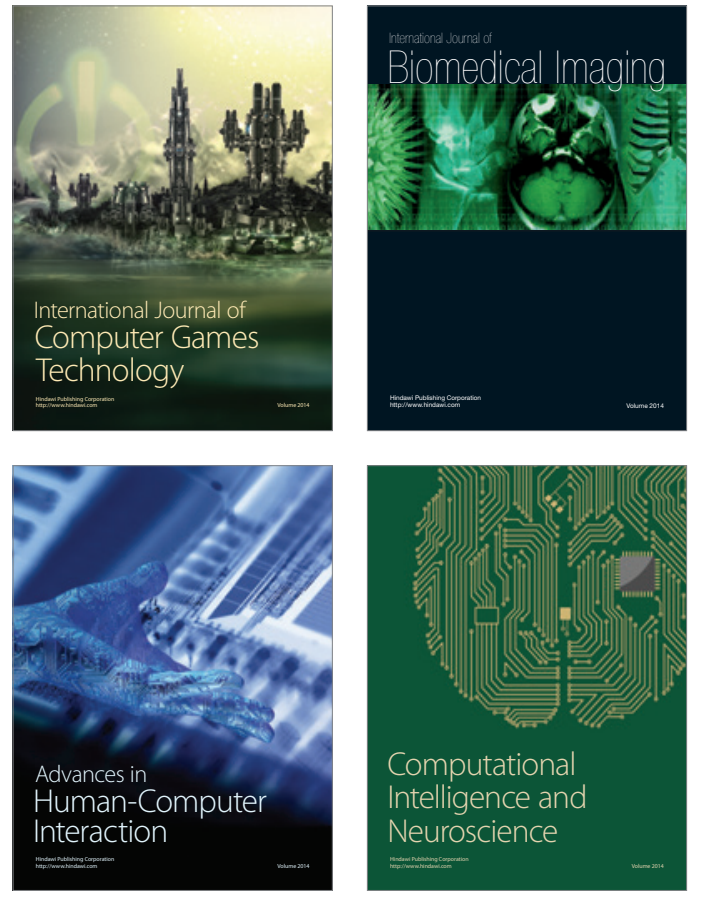
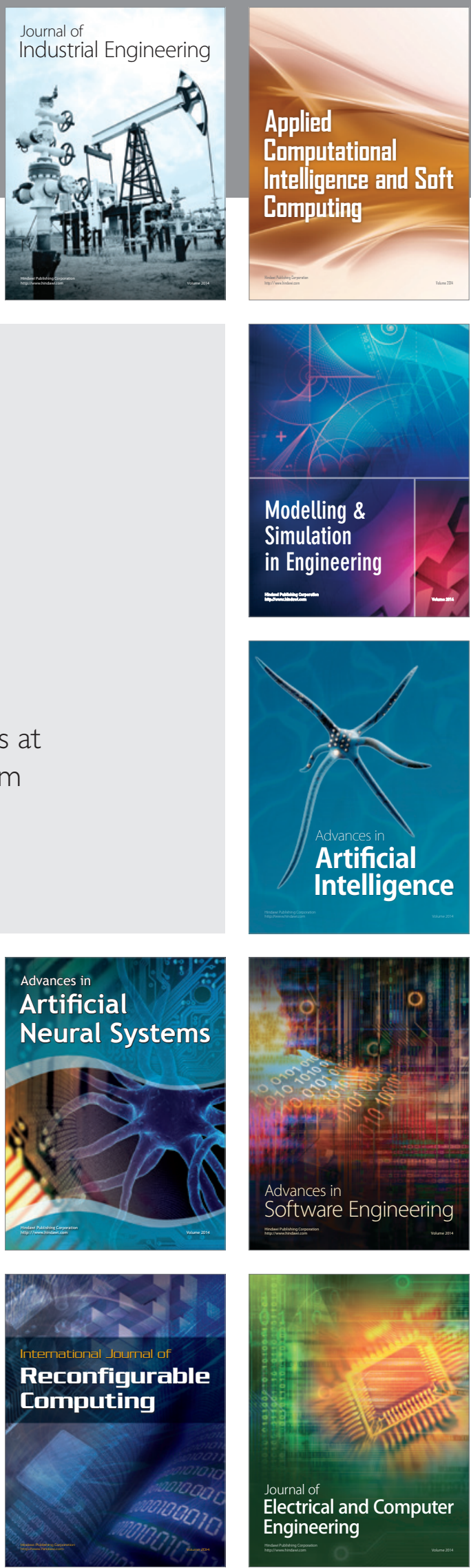